This document is available under a CC-BY-NC-ND license. 


\title{
Surface-active ionic liquids in catalysis: Impact of structure and concentration on the aerobic oxidation of octanol in water
}

\author{
Alice Cognigni ${ }^{\mathrm{a}}$, Sebastian Kampichler ${ }^{\mathrm{a}}$, Katharina Bica ${ }^{\mathrm{a}, *}$ \\ ${ }^{a}$ Institute of Applied Synthetic Chemistry, Vienna University of Technology, Getreidemarkt \\ 9/163, 1060 Vienna, Austria
}

\begin{abstract}
We present design and synthesis of surface-active ionic liquids for the application in micellar catalysis. A series of 1-methyl-3-dodecylimidazolium based ionic liquids with variable core structures including dicationic and zwitterionic ones was synthesized and characterized. These surface-active ionic liquids where applied in the aerobic oxidation of aliphatic alcohols to carbonyl compounds. A strong dependence on the ionic liquid concentration and structure was identified, which is in accordance with the concepts of micellar catalysis. Optimum conditions for the oxidation of 1-octanol could be identified, and the use of surface-active ionic liquids strongly improved the reaction performance compared to pure water. Under optimized conditions, it was possible to isolate up to $75 \%$ of octanoic acid using only small amounts of surface-active ionic liquid in a $0.05 \mathrm{mM}$ solution in water without further ligands.
\end{abstract}

Keywords: micellar catalysis, water, surfactants, ionic liquids, aerobic oxidation, Palladium

2010 MSC: 00-01, 99-00

\section{Introduction}

Solvent consumption accounts for a relevant part of the overall environmental impact of a chemical process. Replacing traditional volatile organic solvents with more benign ones such as water can be a key step towards the develop5 ment of sustainable processes, although problems with substrate solubility may exist. [1] The addition of commercially available surfactants provides a powerful tool to overcome the solubility issue of many organic substrates in water, as the formation of aggregates in water enables the solubilization of reaction mixtures in water. Micelles or higher aggregates have the capability to drastically alter

\footnotetext{
*Corresponding author Katharina Schröder (née Katharina Bica), Fax: +43 158801 16360; Tel: +43158801 163601 .

Email address: katharina.schroeder@tuwien.ac.at (Katharina Bica)
} 
reaction rates, as the local concentration experienced by the reactants in the supramolecular assembly is higher than in a bulk solution. 2] Moreover, recent developments on the engineering of designer surfactants for a specific reaction showed a drastic impact on activity and selectivity through specific interactions between micelle, substrates and catalysts. 3.

15 For this purpose ionic liquids with a long alkyl chain have been recently intensely investigated. It has been demonstrated that ionic liquids with alkyl chains longer than 8 carbon atoms behave like amphiphiles and are able to form micelles in aqueous solution, which renders them ideal candidates as tailormade surfactants for a number of applications. 4, 5. Micellar aggregates of

20 surface-active ionic liquids can increase the solubility of organic compounds such as toluene in water $\underline{6}$, and are even suitable for the extraction of natural compounds. [7 Moreover, the lipophilic core of ionic liquid aggregates in water can act as nanoreactor and exhibit strong kinetic effects on organic reactions. 8, 9, 10, 11 While research on the aggregation behaviour of ionic 25 liquids in water focuses mainly on monocationic alkyl imidazolium based ionic liquids, studies on the adjustments of head group, side chain or counterion structure have also been performed. This high tunability of ionic liquids provides a powerful tool for the design of the optimal environment for a specific reaction in water. 12 .

Based on these considerations, we expanded our recent research on the design of surface-active ionic liquids for micellar catalysis towards the application in aerobic oxidations. In here, we report a study on the ligand free, unsupported, monometallic Pd catalysed oxidation of 1-octanol to octanoic acid in water with the aid of surface-active imidazolium-based ionic liquids and discuss impact of onic liquid structure and concentration in water.

Oxidation reactions are among the most useful transformations and a key step for the synthesis of intermediates in organic chemistry. However, conventional methods relying on reagents such as Dess-Martin periodinane, Swern reagent, or the tetrapropylammonium perruthenate (TPAP)/N-methylmorpholine-

40 N-oxide system exhibit low atom economy. These methods suffer from high waste production due to the by-products formed by the deactivation of the oxidizing agent after the reaction and are difficult to implement at industrial level.[13 As a result, research has focused on the development of more benign oxidations protocols, particularly on catalytic versions that operate under milder 45 conditions and reduce waste. [14, 15] Among different proposed catalysts Palladium is a prime candidate, and homogenous catalysts based on Palladium with a number of ligands have been intensely investigated. Recently Muldoon et al. and Cámpora et al. reported a new series of N,O-ligated Pd(II) complexes based on pyridine-carboxylate and quinoline ligands which are competitive with the so

50 far reported ones in term of turn-over frequency (TOF). [16, 17, 18, In general, dioxygen is considered as the most appealing oxidant used in combination with homogenous Palladium-catalysts as it is cheap, abundant and produces just water as by-product. However, due to safety issues, it should be used in diluted gas mixtures and/or in combination with non-flammable solvents such as water. As ${ }_{55}$ a consequence, Sheldon et al. reported highly efficient ligand systems based 
on bathphenanthroline disulfonate, which allows to perform the Palladiumcatalyzed oxidation of alcohols under aqueous conditions. [19, 20, 21] To obtain acceptable reaction rates for poor water soluble alcohols addition of co-solvents or additives were required. Recent research on Palladium-catalyzed aerobic oxidations of alcohols under aqueous conditions also suggest the use of watersoluble $N$-heterocyclic carbene ligands. 22. Han et al. reported the Palladium catalyzed aerobic oxidation of 1-heptanol in water using 1,3-dialkylimidazoliumbased ligands with a quaternary ammonium moiety. 223] Alternatively, heterogeneous catalysts relying on Palladium-based nanomaterials have been reported

${ }_{65}$ for the oxidation of alcohols to carbonyl compounds. 24.

A number of aspects render surface-active ionic liquids in water an interesting alternative as reaction media in aerobic oxidations under aqueous conditions. Apart from the solubilization of the reaction mixture in water, surface-active ionic liquids, can, and have been, used to increase reaction rates, activity, and

70 selectivity according to the concepts of micellar catalysis. 25, 26] Moreover, the impact of improved solubility is not limited to starting materials or catalyst species: Even though oxygen has generally low solubility in aqueous solutions, it has been reported that micelles can improve the oxygen concentration dissolved in the solution, therefore facilitating the oxidation of subtrates solubilized in the

75 aggregates. 27. Eventually, the role of the surface-active ionic liquid is not limited to the use as mere surfactant; moreover it can interact with the catalytically active species in oxidation reactions, either as $N$-heterocyclic carbene ligands or as stabilizer of in situ formed catalytically active Palladium nanoparticles.

\section{Materials and methods}

80

General

Commercially available reagents and solvents were used as received from Sigma Aldrich unless otherwise specified. Doubly-distilled deionized water was obtained from a Millipore Milli-Q water purification system (Millipore, USA). All ionic liquids were dried for at least $48 \mathrm{~h}$ at room temperature and $0.01 \mathrm{mbar}$

For the characterization of the surface activity of the investigated ionic liquids the same procedure used in our previous work was followed. 9 Solutions at various concentration of the ionic liquids were prepared with doubly-distilled Millipore Milli-Q water and left under shaking at $360 \mathrm{~min}^{-1}$ for $24 \mathrm{~h}$ at room temperature (RT) to equilibrate. For conductivity measurements, samples were previously equilibrated at $(25 \pm 0.1){ }^{\circ} \mathrm{C}$ in a HAAKE K15 thermostat. Conductivity measurement were performed on a Mettler Toledo Seven Excellence system, equipped with a InLAB 741-ISM electrode (cell constant $\kappa=0.105$ ). The conductimeter was calibrated with a standard $\mathrm{KCl}$ solution and two in95 dependent measurements were performed. The CMC was calculated as the intersection point of the two linear regimes in the conductivity/concentration graph. The degree of counter ion binding was calculated with the following equation $\beta=1-\alpha$, where $\alpha$ is the degree of ionization and corresponds to the 
ratio of the slopes between the two linear fragments of the conductivity curves. Surface tension was determined with the Du Noüy ring method on a Krüss manual tensiometer K6 at room temperature. Each measurement was repeated 5 times.

${ }^{1} \mathrm{H}$ and ${ }^{13} \mathrm{C}$ NMR spectra were recorded on a Bruker AC 200 or 400, using the solvent peak as reference. Infrared spectra were recorded on a Perkin-Elmer

105 Spectrum 65 FT IR spectrometer equipped with a Specac MK II Golden Gate Single Reflection ATR unit. Gas chromatography analyses were carried out using a Thermo Scientific Focus gas chromatograph equipped with a BGB5 column BGB-5 (30 m x $0.25 \mathrm{~mm}$ i.d., $0.5 \mathrm{~m}$ film thickness) cross-bonded dimethyl polysiloxane capillary column and a FID detector. The following conditions were employed: Inlet temperature, $260{ }^{\circ} \mathrm{C}$; split ratio 20 ; He carrier gas, $2 \mathrm{ml} / \mathrm{min}$; detector temperature, $280{ }^{\circ} \mathrm{C}$. The temperature program applied for the detection of octanal $\left(\mathrm{t}_{r}=5.2 \mathrm{~min}\right)$, 1-octanol $\left(\mathrm{t}_{r}=5.9 \mathrm{~min}\right)$, methyl benzoate (internal standard, $\left.\mathrm{t}_{r}=6.2 \mathrm{~min}\right)$, octanoic acid $\left(\mathrm{t}_{r}=6.8 \mathrm{~min}\right)$ and octanoic acid octyl ester $\left(\mathrm{t}_{r}=9.9 \mathrm{~min}\right)$ was the following: Initial column temperature

${ }_{115} 60{ }^{\circ} \mathrm{C}$, heating to $170{ }^{\circ} \mathrm{C}$ at a rate of $15{ }^{\circ} \mathrm{C} / \mathrm{min}$, heating to $300{ }^{\circ} \mathrm{C}$ at a rate of $50^{\circ} \mathrm{C} / \mathrm{min}$, final temperature held 5 minutes.

\section{Sythesis of ionic liquids}

Synthesis of $\left[\mathrm{C}_{12} \mathrm{mim}\right] \mathrm{X}$, with $\mathrm{X}=\mathrm{Cl}^{-}(\mathbf{1})$ and $\mathrm{Br}^{-}(\mathbf{3})$ : The halide-based imidazolium salts were synthesized following standard procedures, including the

120 alkylation of $N$-methylimidazole or 1,2-dimethyl imidazole with the appropriate alkyl halide to yield the corresponding imidazolium halide that were repeatedly crystallized for purification. Details can be found in our previous work. 9 ]

1-Dodecyl-2,3-dimethylimidazolium chloride (2). 1,2-Dimethylimidazole (7.99 $\mathrm{g}, 8.3 \mathrm{mmol}$ ) was placed in a three necks round bottom flask equipped with a 125 condenser and an dropping funnel. 1-Chlorododecane (18.7 g, $9.1 \mathrm{mmol}, 1.1 \mathrm{eq})$ were slowly added at room temperature. The reaction was left stirring at $100{ }^{\circ} \mathrm{C}$ for 4 days until NMR analysis showed complete conversion. Remaining volatiles were removed under reduced pressure, and the crude product was recrystallized from THF to obtain a colourless crystalline solid in $95 \%$ yield. ${ }^{1} \mathrm{H}-\mathrm{NMR}(200$ $\left.{ }_{130} \mathrm{MHz}, \mathrm{CDCl}_{3}\right): \delta(\mathrm{ppm})=7.86(1 \mathrm{H}, \mathrm{d}, J=1.90 \mathrm{~Hz}, \mathrm{NCH}=\mathrm{CH}), 7.49(1 \mathrm{H}, \mathrm{d}$, $J=1.92 \mathrm{~Hz}, \mathrm{NCH}=\mathrm{CH}), 4.17\left(2 \mathrm{H}, \mathrm{t}, J=7.41 \mathrm{~Hz}, \mathrm{CH}_{2} \mathrm{C}_{11} \mathrm{H}_{23}\right), 4.01(3 \mathrm{H}, \mathrm{s}$, $\left.\mathrm{NCH}_{3}\right), 2.77\left(3 \mathrm{H}, \mathrm{s}, \mathrm{N}=\mathrm{C}-\mathrm{CH}_{3}\right), 1.75\left(2 \mathrm{H}, \mathrm{t}, J=6.88 \mathrm{~Hz}, \mathrm{CH}_{2} \mathrm{CH}_{2} \mathrm{C}_{10} \mathrm{H}_{21}\right)$, $1.19\left(18 \mathrm{H}, \mathrm{m}, \mathrm{C}_{2} \mathrm{H}_{4} \mathrm{C}_{9} \mathrm{H}_{18} \mathrm{CH}_{3}\right), 0.81\left(3 \mathrm{H}, \mathrm{t}, J=6.10 \mathrm{~Hz}, \mathrm{C}_{11} \mathrm{H}_{22} \mathrm{CH}_{3}\right)$. Analytical data was in accordance with literature. 28.

135 Synthesis of dicationic and zwitterionic surface-active ionic liquids: The remaining ionic liquids were synthesized through a two step procedure involving the alkylation of 1-dodecylimidazole, which was previously synthesized following a procedure reported in literature and distilled before use. [29]

1,3-Bis(3-dodecanimidazolium-1-yl)methane dibromide (4). 1-Dodecylimidazole 140 (4.32 g, $18.3 \mathrm{mmol}, 2.1 \mathrm{eq}$ ) was dissolved in $15 \mathrm{ml}$ of THF and $1.59 \mathrm{~g}$ of dibromomethane $(9.1 \mathrm{mmol}, 1 \mathrm{eq})$ were added at room temperature. The mixture 
was heated to $65{ }^{\circ} \mathrm{C}$ for 5 days. After evaporation of the solvent, the product was dissolved in a small amount of $\mathrm{CH}_{2} \mathrm{Cl}_{2}$ and precipitated by adding EtOAc. The product was obtained via filtration in $10 \%$ yield as a colourless solid. ${ }^{1} \mathrm{H}$ $\operatorname{NMR}\left(400 \mathrm{MHz}, \mathrm{CDCl}_{3}\right): \delta(\mathrm{ppm})=10.77(\mathrm{~s}, 2 \mathrm{H},-\mathrm{N}-\mathrm{C} H=\mathrm{N}-), 8.95(\mathrm{~s}, 2 \mathrm{H}$, $\left.-\mathrm{N}-\mathrm{CH} H_{2}-\mathrm{N}-\right), 7.53(\mathrm{~s}, 2 \mathrm{H}, \mathrm{NCH}=\mathrm{CH}), 7.44(\mathrm{~s}, 2 \mathrm{H}, \mathrm{NCH}=\mathrm{CH}), 4.22(\mathrm{t}, 4 \mathrm{H}$, $\left.J=7.64 \mathrm{~Hz}, \mathrm{CH}_{2} \mathrm{C}_{11} \mathrm{H}_{23}\right), 1.88\left(\mathrm{~m}, 4 \mathrm{H}, \mathrm{CH}_{2} \mathrm{CH}_{2} \mathrm{C}_{10} \mathrm{H}_{21}\right), 1.22-1.13(\mathrm{~m}, 36 \mathrm{H}$, $\left.\mathrm{C}_{2} \mathrm{H}_{4} \mathrm{C}_{9} \mathrm{H}_{18} \mathrm{CH}_{3}\right), 0.80$ (t, $6 \mathrm{H}, J=6.78 \mathrm{~Hz}, \mathrm{C}_{11} \mathrm{H}_{22} \mathrm{CH}_{3}$ ). Analytical data was in accordance with literature. 30 .

1,3-Bis(3-dodecanimidazolium-1yl)propane dibromide (5). 1-Dodecylimidazole $(3.5 \mathrm{~g}, 14.8 \mathrm{mmol}, 2.1 \mathrm{eq})$ were dissolved in $30 \mathrm{ml}$ of THF and $1.49 \mathrm{~g}$ of 1,3dibromopropane $(7.4 \mathrm{mmol}, 1 \mathrm{eq})$ were added at room temperature. The mixture was heated to $65{ }^{\circ} \mathrm{C}$ for 5 days. After evaporation of the solvent, the product was dissolved in a small amount of $\mathrm{CH}_{2} \mathrm{Cl}_{2}$ and precipitated by adding 155 EtOAc. The product was collected via filtration and obtained in $84 \%$ yield as a colourless solid. $\mathrm{mp}=62.6{ }^{\circ} \mathrm{C} . \nu_{\max }\left(\mathrm{cm}^{-1}\right)=3132(\mathrm{C}-\mathrm{H}$ Ar $), 2919(\mathrm{C}-$ $\mathrm{H}), 2851(\mathrm{C}-\mathrm{H}), 1571(\mathrm{C}=\mathrm{C}), 1468(\mathrm{C}=\mathrm{C}), 1161(\mathrm{C}-\mathrm{N}) .{ }^{1} \mathrm{H}-\mathrm{NMR}(400 \mathrm{MHz}$, $\left.\mathrm{CDCl}_{3}\right): \delta(\mathrm{ppm})=10.15(\mathrm{~s}, \mathrm{~N}-\mathrm{CH}=\mathrm{N}-), 8.22(\mathrm{~s}, 2 \mathrm{H},-\mathrm{NCH}=\mathrm{CH}-), 7.30(\mathrm{~s}$,

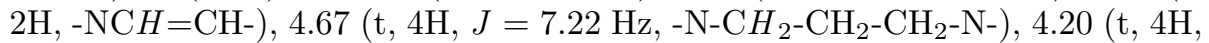

${ }_{160} J=7.48 \mathrm{~Hz}, \mathrm{CH}_{2} \mathrm{C}_{11} \mathrm{H}_{23}$ ), 2.83 (quint, $2 \mathrm{H}, J=7.25 \mathrm{~Hz},-\mathrm{N}_{-} \mathrm{CH}_{2}-\mathrm{CH}_{2}-\mathrm{CH}_{2}$ $\mathrm{N}-) 1.85\left(\mathrm{~m}, 4 \mathrm{H},-\mathrm{CH}_{2} \mathrm{CH}_{2} \mathrm{C}_{10} \mathrm{H}_{21}\right), 1.27-1.13\left(\mathrm{~m}, 36 \mathrm{H}, \mathrm{C}_{2} \mathrm{H}_{4} \mathrm{C}_{9} \mathrm{H}_{18} \mathrm{CH}_{3}\right), 0.80$ $\left(\mathrm{t}, 6 \mathrm{H}, J=6.80 \mathrm{~Hz}, \mathrm{C}_{11} \mathrm{H}_{22} \mathrm{CH}_{3}\right) .{ }^{13} \mathrm{C}-\mathrm{NMR}\left(100 \mathrm{MHz}, \mathrm{CDCl}_{3}\right): \delta(\mathrm{ppm})=$ $136.46,123.83, \quad 121.60, \quad 50.26, \quad 46.71, \quad 31.82, \quad 30.88, \quad 30.08$, $29.52,29.43,29.32,29.26,28.92,26.27,22.60,14.06$.

1,5-Bis(3-dodecanimidazolium-1-yl)pentane dibromide (6). 1-Dodecyimidazole $(3.5 \mathrm{~g}, 14.27 \mathrm{mmol}, 2.1 \mathrm{eq})$ was dissolved in $30 \mathrm{ml}$ of THF and $1.64 \mathrm{~g}$ of 1,5dibromopentane $(7.13 \mathrm{mmol}, 1 \mathrm{eq})$ were added at room temperature. The mixture was heated to $65{ }^{\circ} \mathrm{C}$ for 5 days. After evaporation of the solvent, the product was dissolved in a small amount of $\mathrm{CH}_{2} \mathrm{Cl}_{2}$ and precipitated by adding EtOAc. The product was collected via filtration and obtained in $80 \%$ yield as a colourless solid. $\mathrm{mp}=95.8{ }^{\circ} \mathrm{C} . \nu_{\max }\left(\mathrm{cm}^{-1}\right)$ : $3120(\mathrm{C}-\mathrm{H} \mathrm{Ar}), 2921(\mathrm{C}-$ $\mathrm{H}), 2852(\mathrm{C}-\mathrm{H}), 1561(\mathrm{C}=\mathrm{C}), 1459(\mathrm{C}=\mathrm{C}), 1158(\mathrm{C}-\mathrm{N}) .{ }^{1} \mathrm{H}-\mathrm{NMR}(400 \mathrm{MHz}$, $\left.\mathrm{CDCl}_{3}\right): \delta(\mathrm{ppm})=10.31(\mathrm{~s}, 2 \mathrm{H},-\mathrm{N}-\mathrm{CH}=\mathrm{N}-), 8.10(\mathrm{~s}, 2 \mathrm{H}, \mathrm{NCH}=\mathrm{CH}-), 7.32$ $(\mathrm{s}, 2 \mathrm{H},-\mathrm{NCH}=\mathrm{CH}-), 4.44\left(\mathrm{t}, 4 \mathrm{H}, J=7.06 \mathrm{~Hz},-\mathrm{N}-\mathrm{CH}_{2}-\mathrm{C}_{3} \mathrm{H}_{6}-\mathrm{CH}_{2}-\mathrm{N}-\right), 4.23$ $175 \quad\left(\mathrm{t}, 4 \mathrm{H}, J=7.46 \mathrm{~Hz}, \mathrm{CH}_{2} \mathrm{C}_{11} \mathrm{H}_{23}\right), 2.05\left(\mathrm{~m}, 4 \mathrm{H},-\mathrm{N}_{-} \mathrm{C}_{2} \mathrm{H}_{4}-\mathrm{CH}_{2}-\mathrm{C}_{2} H_{4}-\mathrm{N}-\right), 1.85$

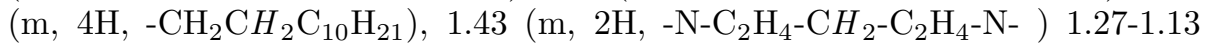
$\left(\mathrm{m}, 36 \mathrm{H}, \mathrm{C}_{2} \mathrm{H}_{4} \mathrm{C}_{9} \mathrm{H}_{18} \mathrm{CH}_{3}\right), 0.80\left(\mathrm{t}, 6 \mathrm{H}, J=6.82 \mathrm{~Hz}, \mathrm{C}_{11} \mathrm{H}_{22} \mathrm{CH}_{3}\right) .{ }^{13} \mathrm{C}-$ $\operatorname{NMR}\left(100 \mathrm{MHz}, \mathrm{CDCl}_{3}\right): \delta(\mathrm{ppm})=136.61,123.53,121.54,50.05,49.01,31.80$, $30.23,29.51,29.42,29.32,29.24,29.11,28.92,26.23,22.59,22.01,14.05$.

180 4-(1-Dodecyl-3-midazolium)butansulfonate (7). 1-Dodedecylimidazole (3.17 g, $13.42 \mathrm{mmol}, 1 \mathrm{eq})$ were dissolved in $5 \mathrm{ml}$ of THF and a solution of $2.01 \mathrm{~g}$ 1,4-butansultone (14.76 mmol, $1.1 \mathrm{eq})$ in $5 \mathrm{ml}$ of THF was added dropwise at $0{ }^{\circ} \mathrm{C}$. The reaction mixture was warmed to room temperature and stirred for 6 days at $65{ }^{\circ} \mathrm{C}$. The obtained precipitate was collected via filtration. The 
crude product was washed with diethylether three times to obtain the product in $77 \%$ yield as a colourless solid. $\mathrm{mp}=106.3{ }^{\circ} \mathrm{C} . \nu_{\max }\left(\mathrm{cm}^{-1}\right): 3133(\mathrm{C}-\mathrm{H}$ Ar), $2919(\mathrm{C}-\mathrm{H}), 2848(\mathrm{C}-\mathrm{H}), 1567(\mathrm{C}=\mathrm{C}), 1469(\mathrm{C}=\mathrm{C}), 1185(\mathrm{C}-\mathrm{N}, \mathrm{S}=\mathrm{O})$, $1037(\mathrm{~S}-\mathrm{O}) .{ }^{1} \mathrm{H}-\mathrm{NMR}\left(100 \mathrm{~Hz}, \mathrm{CDCl}_{3}\right): \delta(\mathrm{ppm})=9.72(\mathrm{~s}, 1 \mathrm{H},-\mathrm{N}-\mathrm{C} H=\mathrm{N}-)$, $7.72(\mathrm{~s}, 1 \mathrm{H},-\mathrm{NCH}=\mathrm{CH}-), 7.23(\mathrm{~s}, 1 \mathrm{H},-\mathrm{NCH}=\mathrm{CH}-), 4.32(\mathrm{t}, 2 \mathrm{H}, J=7.18 \mathrm{~Hz}$, $\left.-\mathrm{N}-\mathrm{CH}_{2}-\mathrm{C}_{3} \mathrm{H}_{6}-\mathrm{SO}_{3}\right), 4.15\left(\mathrm{t}, 2 \mathrm{H}, J=7.38 \mathrm{~Hz}, \mathrm{CH}_{2} \mathrm{C}_{11} \mathrm{H}_{23}\right), 2.80(\mathrm{t}, 2 \mathrm{H}, J=$

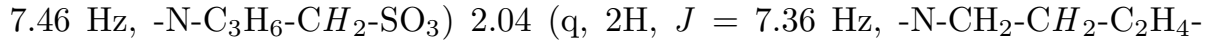
$\left.\mathrm{SO}_{3}\right) 1.80\left(\mathrm{~m}, 4 \mathrm{H}, \mathrm{O}_{3} \mathrm{~S}-\mathrm{CH}_{2}-\mathrm{CH}_{2}-\mathrm{C}_{2} \mathrm{H}_{4}-\mathrm{N}-\mathrm{CH}-\mathrm{N}-\mathrm{CH}_{2} \mathrm{CH}_{2} \mathrm{C}_{10} \mathrm{H}_{21}\right), 1.24-1.13$ $\left(\mathrm{m}, 18 \mathrm{H}, \mathrm{C}_{2} \mathrm{H}_{2} \mathrm{C}_{9} \mathrm{H}_{18} \mathrm{CH}_{3}\right), 0.80\left(\mathrm{t}, 3 \mathrm{H}, J=6.82 \mathrm{~Hz}, \mathrm{C}_{11} \mathrm{H}_{22} \mathrm{CH}_{3}\right) \cdot{ }^{13} \mathrm{C}-\mathrm{NMR}$ $\left(100 \mathrm{MHz}, \mathrm{CDCl}_{3}\right): \delta(\mathrm{ppm})=137.23,123.08,121.53,50.86,49.90,49.38,31.85$, $30.20,29.56,29.49,29.37,29.31,29.29,29.00,26.28,22.63,22.16,14.08$.

Poly(ethylene glycol) functionalized dicationic ionic liquid $/ C_{11}$ im-PEG1000$C_{11} \mathrm{im} J \mathrm{Cl}_{2} 8$ ). The synthesis was performed adapting procedures already described in literature for the derivatization of PEG1000 to dichloro-PEG1000. 31, 32. Subsequently $1.77 \mathrm{~g}$ of dichloro-PEG1000 (1.7 mmol, $1 \mathrm{eq})$ were mixed with $200 \quad 0.93 \mathrm{~g}$ of 1-dodecylimidazole $(3.9 \mathrm{mmol}, 2.3 \mathrm{eq})$ and stirred for 4 days at $90{ }^{\circ} \mathrm{C}$ under argon. The product was washed several times with EtOAc and obtained as an orange viscose liquid in $89 \%$ yield. $\mathrm{mp}=28.4^{\circ} \mathrm{C} . \nu_{\max }\left(\mathrm{cm}^{-1}\right): 2921$ $(\mathrm{C}-\mathrm{H}), 2854(\mathrm{C}-\mathrm{H}), 1563(\mathrm{C}=\mathrm{C}), 1457(\mathrm{C}=\mathrm{C}), 1103(\mathrm{C}-\mathrm{O}-\mathrm{C}) .{ }^{1} \mathrm{H}-\mathrm{NMR}(400 \mathrm{~Hz}$, $\left.\mathrm{CDCl}_{3}\right): \delta(\mathrm{ppm})=10.54(\mathrm{~s}, 2 \mathrm{H},-\mathrm{N}=\mathrm{C} H-\mathrm{N}-), 7.65(\mathrm{~s}, 2 \mathrm{H},-\mathrm{NCH}=\mathrm{CH}-), 7.21$ $(\mathrm{s}, 2 \mathrm{H},-\mathrm{NCH}=\mathrm{CH}-), 4.60\left(\mathrm{t}, 4 \mathrm{H}, J=4.42 \mathrm{~Hz},-\mathrm{CH}_{2^{-}}\right), 4.19(\mathrm{t}, 6 \mathrm{H}, J=7.58$ $\left.\mathrm{Hz},-\mathrm{CH}_{2^{-}}\right), 3.92\left(\mathrm{t}, 4 \mathrm{H}, J=4.46 \mathrm{~Hz},-\mathrm{CH}_{2^{-}}\right), 3.603 .53(\mathrm{~m}, \mathrm{PEG}), 1.83(\mathrm{t}, 4 \mathrm{H}$, $\left.J=6.36 \mathrm{~Hz}, \mathrm{CH}_{2} \mathrm{CH}_{2} \mathrm{C}_{10} \mathrm{H}_{21}\right), 1.18\left(\mathrm{~m}, 41 \mathrm{H}, \mathrm{C}_{2} \mathrm{H}_{4} \mathrm{C}_{9} H_{18} \mathrm{CH}_{3}\right), 0.88$ (t, $6 \mathrm{H}, J$ $=6.84 \mathrm{~Hz}, \mathrm{C}_{11} \mathrm{H}_{22} \mathrm{CH}_{3}$ ).

\section{Oxidation procedures}

Representing procedure for the oxidation of 1-octanol at atmospheric pressure. As general procedure to perform the oxidation of 1-octanol at 1 bar a stock solution of $\mathrm{Pd}(\mathrm{OAc})_{2}(4.48 \mathrm{mg} / \mathrm{ml})$ in EtOAc was prepared. This stock solution $(1 \mathrm{ml})$ was placed in a $20 \mathrm{ml}$ vial. The vial was placed under reduced pressure for $5 \mathrm{~h}$ to remove the solvent. Stock solutions of ionic liquids at different con215 centrations were prepared in water that also contained the base $\mathrm{K}_{2} \mathrm{CO}_{3}(13.8$ $\mathrm{mg} / \mathrm{ml})$. The stock solution of ionic liquid and base in water $(2 \mathrm{ml})$ was added to a vial containing the catalyst, followed by $63.3 \mu \mathrm{l}$ of 1-octanol. A balloon filled with $\mathrm{O}_{2}$ was placed on top of the vial with a syringe needle through a septum. The vials were then placed in a pre-heated stirring block for the desired time and temperature. When the reaction was finished the vials were allowed to cool to room temperature before opening. An excess of $2 \mathrm{M} \mathrm{HCl}$ was added to neutralize the base and the product was extracted with $10 \mathrm{ml}$ EtOAc. An aliquot of the organic layer was taken for GC analysis using methylbenzoate as internal standard.

Representing procedure for the oxidation of 1-octanol under pressure. A $40 \mathrm{ml}$ autoclave was charged with catalyst $22.4 \mathrm{mg}(0.1 \mathrm{mmol})$ and $138 \mathrm{mg}(1 \mathrm{mmol})$ of $\mathrm{K}_{2} \mathrm{CO}_{3}$. The ionic liquid solution in water $(10 \mathrm{ml})$ and $261 \mathrm{mg}(2 \mathrm{mmol})$ of 
1-octanol were added. The autoclave was loaded with air at the desired pressure and left stirring on a heating block for the desired time and temperature. The autoclave was cooled to room temperature prior to the release of the pressure. An excess of $2 \mathrm{M} \mathrm{HCl}$ was added to neutralize the base and the product was extracted with EtOAc. The organic fractions were collected together and diluted to $50 \mathrm{ml}$. An aliquote of this solution was taken for GC analysis using methylbenzoate as internal standard.

235 In order to isolate the product a different work-up procedure was followed: After pressure release an excess of base was added and remaining 1-octanol and by-products were extracted with EtOAc. Afterwards an excess of $\mathrm{HCl}$ was added and octanoic acid was successively extracted with EtOAc. The combined organic fractions were collected and diluted to $50 \mathrm{ml}$. An aliquot $(0.4 \mu \mathrm{l})$ of this solution was taken for GC analysis using methylbenzoate as internal standard. The remaining solution was dried over $\mathrm{Na}_{2} \mathrm{SO}_{4}$. Solvents were removed under reduced pressure to obtain octanoic acid in spectroscopically pure form. ${ }^{1} \mathrm{H}-$ $\operatorname{NMR}\left(200 \mathrm{MHz}, \mathrm{CDCl}_{3}\right): \delta(\mathrm{ppm})=11.32(\mathrm{~s}, 1 \mathrm{H}, \mathrm{COO} H), 2.27(\mathrm{t}, 2 \mathrm{H}, J=$ $7.56 \mathrm{MHz},-\mathrm{CH}_{2}-\mathrm{COOH}$ ), 1.56 (quin, $2 \mathrm{H}, \mathrm{J}=7.35 \mathrm{MHz},-\mathrm{CH}_{2}-\mathrm{CH}_{2}-\mathrm{COOH}$ ), ${ }_{245} 1.23\left(\mathrm{~m}, 8 \mathrm{H}, \mathrm{CH}_{3}-\mathrm{C}_{4} H_{8}-\mathrm{CH}_{2}-\right), 0.80\left(\mathrm{t}, 3 \mathrm{H}, \mathrm{J}=6.88 \mathrm{~Hz},-\mathrm{CH}_{3}\right)$. Analytical data was in accordance with literature. 33.

\section{Results and Discussion}

Design and synthesis of surface-active ionic liquids

Based on our previous experience in cross-coupling chemistry and on recent literature data concerning Palladium-catalyzed oxidation, we focused on the use of imidazolium-based 1-alkylmethylimidazolium-based ionic liquids. These surface-active ionic liquids should not only act as amphiphiles to overcome solubility issues of the alcohol in water, but may directly act as ligands for Palladium. Consequently, a series of known and new surface-active ionic liquids based on 255 the 1-dodecyl-3-methylimidazolium $\left(\left[\mathrm{C}_{12} \mathrm{mim}\right]^{+}\right)$cation including dicationic and zwitterionic structures was synthesized adapting procedures already reported in literature. 34, 35, 29, 32, Different approaches were used and are depicted in Figure 1 .

In case of surface-active ionic liquids $\left[\mathrm{C}_{12} \operatorname{mim}\right] \mathrm{Cl} \mathbf{1},\left[\mathrm{C}_{12} \operatorname{mim}\right] \mathrm{Br} \mathbf{2}$ and $\left[\mathrm{C}_{12} \mathrm{~m}_{2} \mathrm{im}\right] \mathrm{Cl} 3$ the direct alkylation of 1-methylimidazole or 1,2-dimethylimidazole with the desired dodecyl halides gave a straightforward access to the desired surface-active ionic liquids. The products could be obtained as colourless crystals in excellent yields after recrystallization from suitable solvents. The remaining surface-active ionic liquids were synthesized through a two step procedure

265 relying on 1-dodecylimidazole as precursor: For the dicationic surface-active ionic liquids $\left[\mathrm{C}_{12} \mathrm{im}-\mathrm{C}_{1}-\mathrm{C}_{12} \mathrm{im}\right] \mathrm{Br}_{2} 4,\left[\mathrm{C}_{12} \mathrm{im}-\mathrm{C}_{3}-\mathrm{C}_{12} \mathrm{im}\right] \mathrm{Br}_{2} 5$ and $\left[\mathrm{C}_{12} \mathrm{im}-\mathrm{C}_{5^{-}}\right.$ $\left.\mathrm{C}_{12} \mathrm{im}\right] \mathrm{Br}_{2} 6$ the corresponding dibromoalkane was used as alkylating agent with 2 equivalents of 1-dodecylimidazole. Precipitation in ethyl acetate afforded all products as colourless solids. Good yields were obtained for surface-active ionic

270 liquids $\mathbf{5}$ and $\mathbf{6}$, while in the case of $\mathbf{4}$ the high volatility of the starting material dibromomethane strongly limited the reaction results. The zwitterionic 


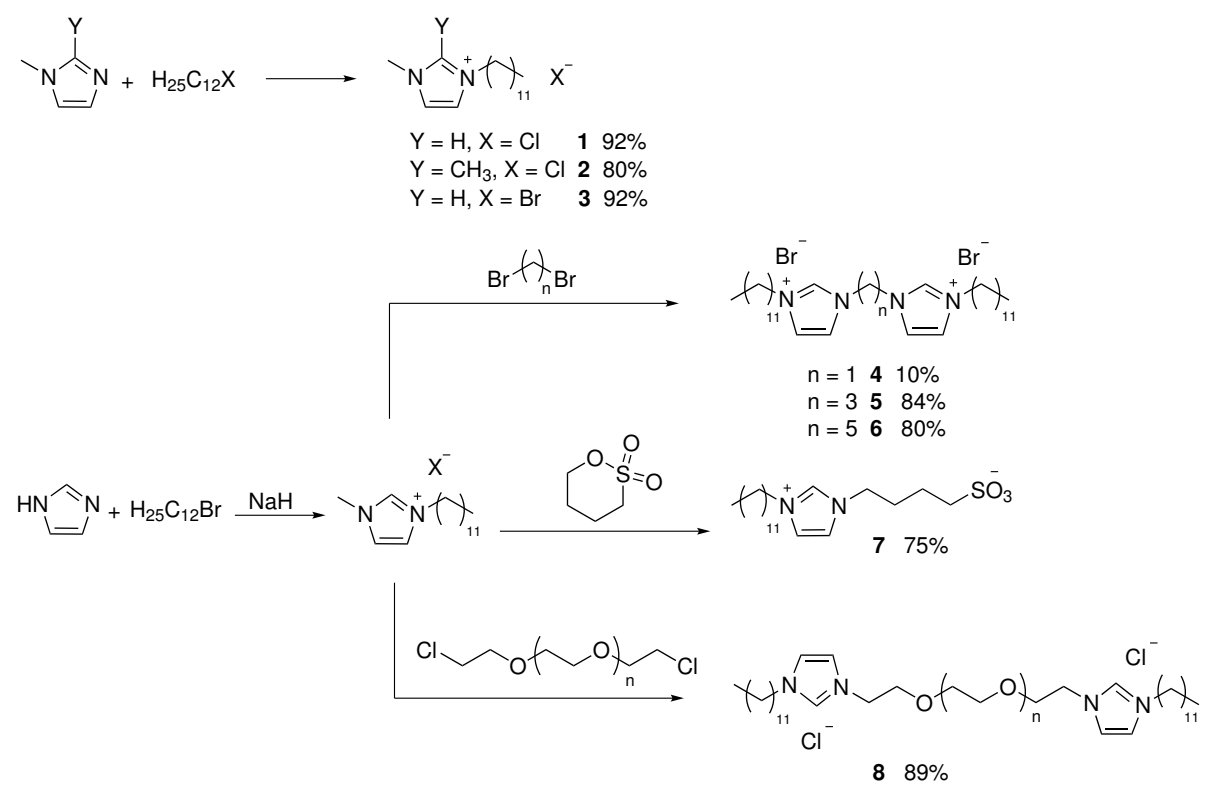

Figure 1: Synthesis of surface-active ionic liquids.

ionic liquid $\left[\mathrm{C}_{12}\right.$ im- $\left.\mathrm{C}_{4}-\mathrm{SO}_{3}\right] \mathbf{7}$ was obtained through the ring opening reaction of 1,4-butane sultone with 1-dodecylimidazole to yield the product as a colourless solid in $77 \%$ yield. In order to synthesize $\left[\mathrm{C}_{12} \mathrm{im}-\mathrm{PEG} 1000-\mathrm{C}_{12} \mathrm{im}\right] \mathrm{Cl}_{2} \mathbf{8}$ 275 an additional step for the derivatization of PEG1000 to the dichloro-PEG1000 prior to the alkylation with 1-dodecylimidazole was necessary. The product was obtained in the second step after washing with EtOAc as an orange wax in $89 \%$ yield.

\section{Characterization of surface-active ionic liquids}

The synthesized ionic liquids were characterized with regard to their surface activity. For this purpose critical micelle concentrations (CMC) were measured with two techniques, surface tension and conductivity, and results are depicted in Figure 2 and 3 , and summarized in Table 1.

In general, imidazolium-based surfactants show a higher surface activity compared to the corresponding ammonium ones due to the delocalized charge on the imidazolium group. 36. The addition of a methyl group on the position 2 of the imidazolium ring slightly lowers the CMC. In addition, the anion plays a relevant role in the aggregation ability of surfactants, since it screens the electrostatic repulsion of the head groups in the micelles. Consequently, a less hydrated anion such as bromide favours micellization over chloride. 9

Dicationic or gemini surfactants consist of two polar head groups with hydrophobic chains, covalently connected through a spacer. 35] In general, dicationic surfactants show a lower CMC than the monoatomic analogous and tend 

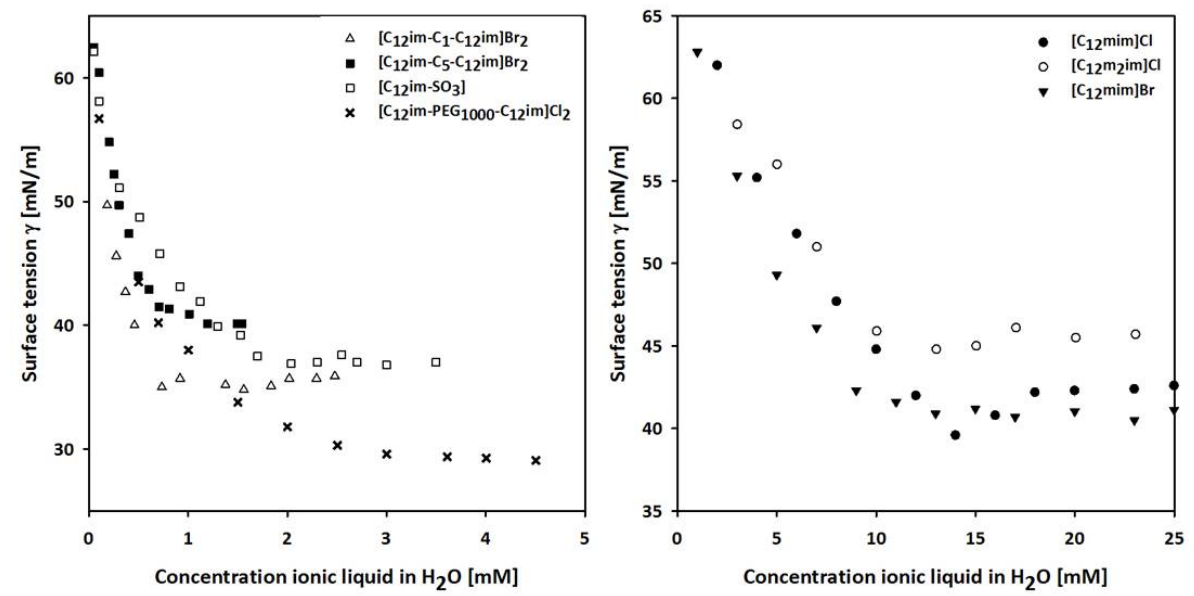

Figure 2: Surface tension of the investigated ionic liquids at $25^{\circ} \mathrm{C}$.
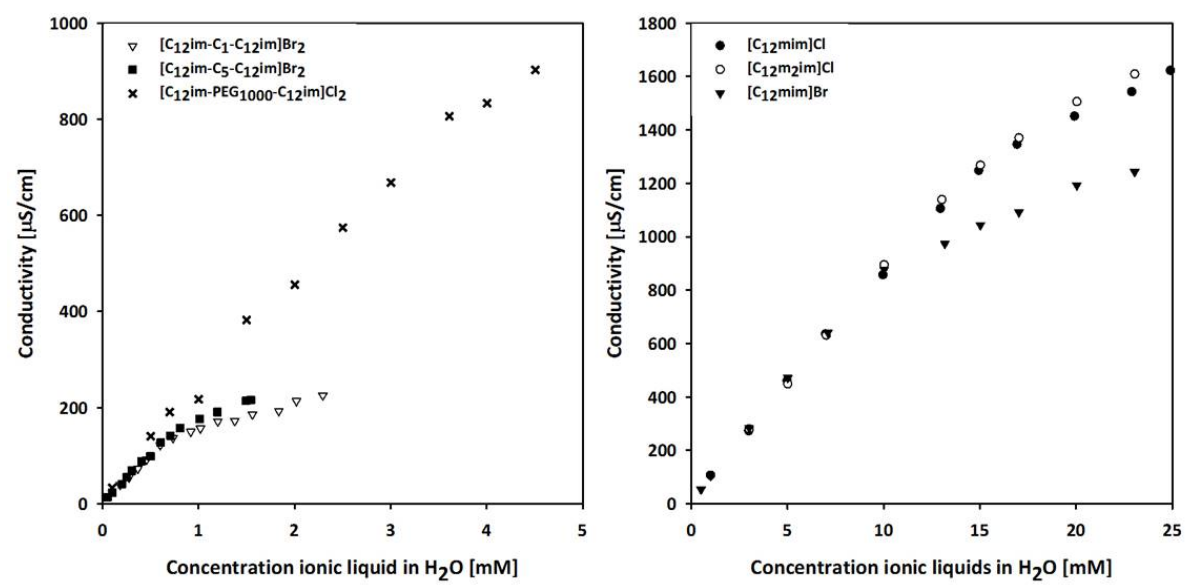

Figure 3: Conductivity of the investigated ionic liquids at $25^{\circ} \mathrm{C}$.

to aggregate forming vesicles like lipids. 30. The length of the spacer has a critical role in the determination of the flexibility of the molecule and hence on the formation of aggregates. As a consequence of these characteristic, a similar CMC was observed for the $\left[\mathrm{C}_{12} \mathrm{im}-\mathrm{C}_{n}-\mathrm{C}_{12} \mathrm{im}\right] \mathrm{Br}_{2}$ series with $n=1$ and 5 , while $n=3$ shows a minimum. A similar behaviour was already identified in a study on $\left[\mathrm{C}_{16} \mathrm{im}-\mathrm{C}_{n}-\mathrm{C}_{16} \mathrm{im}\right] \mathrm{Br}_{2}$ dicationic surfactants with variable spacer length. 37]

300 Since zwitterionic surfactants are not suitable for conductivity measurement, the $\mathrm{CMC}$ of ionic liquid $\left[\mathrm{C}_{12}\right.$ im- $\left.\mathrm{C}_{4}-\mathrm{SO}_{3}\right] 7$ could only be determined by surface tension. Due to the overall neutral charge of the head group zwitterionic 
surfactants have a higher surface activity compared to cationic surfactants, as can be seen in the comparison of surface-active ionic liquids $\left[\mathrm{C}_{12} \mathrm{~m}_{2} \mathrm{im}\right] \mathrm{Cl}$ and $305\left[\mathrm{C}_{12} \mathrm{im}-\mathrm{C}_{4}-\mathrm{SO}_{3}\right]$. Moreover, replacing the ammonium group of sulfobetaine with the imidazolium-based head group resulted in an decrease of the CMC, which is in accordance with literature data on cationic surfactants. 38.

Table 1: Critical micelle concentration (CMC) obtained by surface tension and conductivity for surface-active ionic liquids 1-8.

\begin{tabular}{lll}
\hline Ionic Liquid & $\begin{array}{l}\text { Surface tension } \\
{[\mathrm{mM}]}\end{array}$ & $\begin{array}{l}\text { Conductivity } \\
{[\mathrm{mM}]}\end{array}$ \\
\hline$\left[\mathrm{C}_{12} \mathrm{mim}\right] \mathrm{Cl} \mathbf{1}$ & $13.25[9]$ & $14.53[9]$ \\
{$\left[\mathrm{C}_{12} \mathrm{~m}_{2} \mathrm{im}\right] \mathrm{Cl} \mathbf{2}$} & 10.33 & 13.75 \\
{$\left[\mathrm{C}_{12} \mathrm{mim}\right] \mathrm{Br} \mathbf{3}$} & $9.29[9]$ & $10.29[9]$ \\
{$\left[\mathrm{C}_{12} \mathrm{im}-\mathrm{C}_{1}-\mathrm{C}_{12} \mathrm{im}\right] \mathrm{Br}_{2} \mathbf{4}$} & 0.70 & 0.74 \\
{$\left[\mathrm{C}_{12} \mathrm{im}-\mathrm{C}_{3}-\mathrm{C}_{12} \mathrm{im}\right] \mathrm{Br}_{2} \mathbf{5}$} & $0.53[39]$ & $0.61[39]$ \\
{$\left[\mathrm{C}_{12} \mathrm{im}-\mathrm{C}_{5}-\mathrm{C}_{12} \mathrm{im}\right] \mathrm{Br}_{2} \mathbf{6}$} & 0.63 & 0.70 \\
{$\left[\mathrm{C}_{12} \mathrm{im}-\mathrm{C}_{4}-\mathrm{SO}_{3}\right] \mathbf{7}$} & 1.67 & - \\
{$\left[\mathrm{C}_{12} \mathrm{im}-\mathrm{PEG} \mathrm{P} 1000-\mathrm{C}_{12} \mathrm{im}\right] \mathrm{Cl}_{2} \mathbf{8}$} & 2.26 & 2.91 \\
\hline
\end{tabular}

Optimization of reaction parameters in the aerobic oxidation of 1-octanol

With this set of surface-active ionic liquids with variable structure of the cationic head group in hand, we turned our attention towards the palladiumcatalyzed aerobic oxidation of alcohols in water. We have chosen aliphatic inactivated alcohols, as these are less reactive in catalytic systems and notoriously difficult to oxidize. Our initial experiments focused on the optimization of reaction parameters for the oxidation of 1-octanol at atmospheric pressure. Reactions were carried out using $2 \mathrm{ml}$ of aqueous ionic liquid solution in magnetically stirred vials placed in a metal heating block. Oxygen was used as oxidizing agent and introduced in the system with a balloon through a septum. Results of the initial screening of reaction parameters are summarized in Table 3.

After running the reaction for the indicated time, the crude reaction mixtures were analysed by GC. While traces of side products such as octanal and octyloctanoate ester below $5 \%$ were found, the oxidation proceeded smoothly towards octanoic acid as main product. As already suggested in literature, we found a strong influence of the base. Best results were obtained with potassium 325 carbonate when used in a concentration range of 50-75 mol.\% (Table 3 , entry 2-3). A higher or lower amount led to lower performance (Tab. 2 entry 1 and 4 ), while only traces of product were found when using $\mathrm{NaOAc}$ or the organic base DBU instead. The addition of acetic acid as sometimes suggested in literature did not benefit the reaction. When investigating the impact of catalyst 330 loading, we found that at least $5 \mathrm{~mol} \%$ of $\mathrm{Pd}(\mathrm{OAc})_{2}$ (Table 3 , entry 2 and 7) were necessary in order to obtain satisfactory results. Surprisingly a higher amount did not further improve the yield of octanoic acid (Table 3 , entry 8). 
Table 2: Optimization of the reaction conditions for the oxidation of 1-octanol using 1 bar of $\mathrm{O}_{2}$ as oxidizing agent.

\begin{tabular}{llllll}
\hline Entry $^{\mathrm{a}}$ & $\begin{array}{l}\text { Temperature } \\
{\left[{ }^{\circ} \mathrm{C}\right]}\end{array}$ & $\begin{array}{l}\text { Time } \\
{[\mathrm{h}]}\end{array}$ & $\begin{array}{l}\mathrm{Pd}(\mathrm{OAc})_{2} \\
{[\mathrm{~mol} . \%]}\end{array}$ & $\begin{array}{l}\mathrm{K}_{2} \mathrm{CO}_{3} \\
{[\mathrm{~mol} . \%]}\end{array}$ & $\begin{array}{l}\mathrm{Yield}^{\mathrm{b}} \\
{[\%]}\end{array}$ \\
\hline 1 & 100 & 18 & 5 & 20 & 10 \\
2 & 100 & 18 & 5 & 50 & 64 \\
3 & 100 & 18 & 5 & 75 & 65 \\
4 & 100 & 18 & 5 & 100 & 48 \\
5 & 100 & 18 & 5 & $50^{\mathrm{c}}$ & $<5$ \\
6 & 100 & 18 & 5 & $50^{\mathrm{d}}$ & $<5$ \\
7 & 100 & 18 & 2 & 50 & $<5$ \\
8 & 100 & 18 & 10 & 50 & 56 \\
9 & 100 & 18 & 2.5 & 50 & 58 \\
10 & 25 & 18 & 5 & 50 & $<5$ \\
11 & 50 & 18 & 5 & 50 & $<5$ \\
12 & 80 & 18 & 5 & 50 & 42 \\
13 & 100 & 6 & 5 & 50 & $<5$ \\
14 & 100 & 12 & 5 & 50 & 48 \\
15 & 100 & 24 & 5 & 50 & 71 \\
16 & 100 & 48 & 5 & 50 & 64 \\
$17^{\mathrm{f}}$ & 100 & 18 & 5 & 50 & 5 \\
\hline
\end{tabular}

${ }^{\text {a }}$ Reactions performed using $0.4 \mathrm{mmol}$ of 1-octanol in $2 \mathrm{ml}$ of a $5 \mathrm{mM}\left[\mathrm{C}_{12} \mathrm{mim}\right] \mathrm{Cl}$ solution.

${ }^{\mathrm{b}}$ Yield determined via GC analysis. Results are reported as average of two independent experiments.

${ }^{\mathrm{c}}$ DBU used as base.

d $\mathrm{NaOAc}$ used as base.

e $[\mathrm{Pd}(\text { allyl }) \mathrm{Cl}]_{2}$ used as catalyst.

${ }^{\mathrm{f}}$ Reactions performed with a $5 \mathrm{mM}$ solution of CTAB instead of $\left[\mathrm{C}_{12} \mathrm{mim}\right] \mathrm{Cl}$ solution.

Concerning the effect of temperature on the reaction, the reaction performed poorly at room temperature or $50{ }^{\circ} \mathrm{C}$, while an increased temperature of at least $80^{\circ} \mathrm{C}$ was required to improve the results (Table 3. entry 10-12). Eventually, the highest yield was obtained when running the oxidation at $100{ }^{\circ} \mathrm{C}$ for 24 hours using $5 \mathrm{~mol} . \% \mathrm{Pd}(\mathrm{OAc})_{2}$ and $50 \mathrm{~mol} . \% \mathrm{~K}_{2} \mathrm{CO}_{3}$, and up to $71 \%$ octanoic acid were formed (Table 3, entries 13-16). In order to compare surface-active ionic liquids with conventional surfactants, we also investigated the oxidation 340 using 1-cetyltrimethylammonium bromide $(\mathrm{CTAB})$ instead of $\left[\mathrm{C}_{12} \mathrm{mim}\right] \mathrm{Cl}$ under the optimized conditions. It is important to highlight the superiority of surface active ionic liquids in micellar catalysis in comparison to conventional surfactants, in fact the use of CTAB afforded only $5 \%$ of the product (Table 3. entry 17). A similar effect has been observed by Cole-Hamilton et al. for 
hydroformylation reactions, were imidazolium-based surfactants outperformed ammonium- or pyridinium-based structures. 40.

\section{Impact of ionic liquid concentration}

In order to gain a better understanding on the role of the ionic liquid in the system, different concentrations of ionic liquids $\left[\mathrm{C}_{12} \mathrm{mim}\right] \mathrm{Cl} \mathbf{1}$ were evaluated under the previously optimized conditions using 1 bar of $\mathrm{O}_{2}$ as oxidizing agent. As can be seen in the results reported in Figure 4 , a strong dependence of the yield of octanoic acid with regard to the surfactant concentration was found, which is in accordance with the concepts of micellar catalysis. Moreover, the presence of surface-active ionic liquids in the reaction mixture was essential, as 355 only traces of the product could be identified in pure water as reaction media. As soon as the concentration of $\left[\mathrm{C}_{12} \mathrm{mim}\right] \mathrm{Cl} \mathbf{1}$ reached $1 \mathrm{mM}$ the yield of octanoic acid increased drastically to $50 \%$. This suggests the formation of ionic liquid aggregates, although this concentration is below the $\mathrm{CMC}$ values for pure $\left[\mathrm{C}_{12} \mathrm{mim}\right] \mathrm{Cl} \mathbf{1}$ (Table 2). However, it can be assumed that the presence of catalyst and base renders the CMC to a lower value, which is in accordance with literature data studying salt effects on the aggregation of imidazolium-based ionic liquids. 41]

The best results were obtained with $5 \mathrm{mM}\left[\mathrm{C}_{12} \operatorname{mim}\right] \mathrm{Cl} \mathbf{1}$ which allowed to obtain $64 \%$ of octanoic acid yield. The concentration profile shows a maximum at $5 \mathrm{mM}$ and, as it is usual for micellar catalysis, the performance decreases again above $15 \mathrm{mM}$. Interestingly a different profile was obtained in the case of $\left[\mathrm{C}_{12} \mathrm{~m}_{2} \mathrm{im}\right] \mathrm{Cl} \mathbf{2}$ which allowed to obtain good yields even at high concentrations. The slightly decrease in octanoic acid yield at 10 and $15 \mathrm{mM}$ for $\left[\mathrm{C}_{12} \mathrm{~m}_{2} \mathrm{im}\right] \mathrm{Cl} \mathbf{2}$ can be balanced by the additional formation of the ester octyloctanoate, these were the only conditions at which $5-10 \%$ ester formation was identified.

Further studies showed that the catalyst $\mathrm{Pd}(\mathrm{OAc})_{2}$ is actually decomposing during the reaction, as we observed the formation of heterogeneous Palladium aggregates forming during the oxidation (see ESI Figure S1). This suggest a different catalytically active species compared to Han et al., who reported that structurally related 1,3-dialkylimidazolium compounds containing a quaternary ammonium moiety act as NHC-ligand in this oxidation.

However, the formation of Palladium-based nanoparticles is not uncommon in this reaction. Pioneering work on Palladium nanoparticle mediated oxidations was conducted by Moiseev et al., who reported that a Pd giant cluster was 380 able to catalyse the oxidation of lower alcohols to a series of different products including aldehydes, esters, anhydrides, carboxylic acids and acetals, while benzyl alcohols were oxidized to aldehydes. 42, 43] Different ligands have been used to stabilize Palladium nanoparticles. The previously mentioned neocuprine ligand was also found to stabilize nanoparticles that were catalytically active in the oxidation of 2-hexanol, but also of some steroidal alcohols. [21, 24] Formation of $\mathrm{Pd}$ nanoparticles was mediated by the alcohol itself that acted as reducing agent in the presence of a co-solvent. Other stabilizing agents for Pd nanoparticles used in the oxidation of alcohols include polymers 44 such as polyethylenglycol 


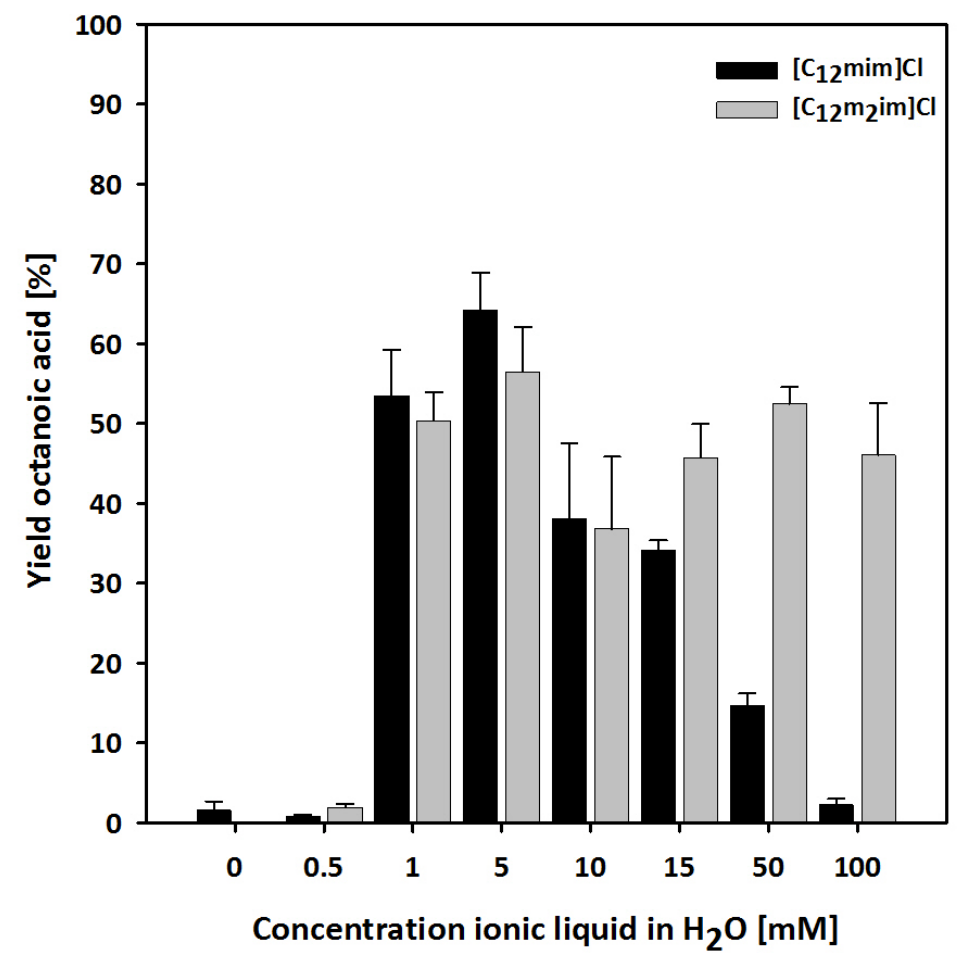

Figure 4: Results for the oxidation of 1-octanol performed with $\left[\mathrm{C}_{12} \mathrm{mim}\right] \mathrm{Cl}$ (dark grey) and $\left[\mathrm{C}_{12} \mathrm{~m}_{2} \mathrm{im}\right] \mathrm{Cl}$ (light gray) at different concentrations. For reaction conditions see Tab.2.

45. 46. Due to the high tendency of Palladium nanoparticles to aggregate several reports on supported nanoparticles emerged lately. [47, 48] However their reactivity is mainly limited to allylic alcohols, while reports of their activity towards aliphatic alcohols is still scarce. 15] Different suggestions were made on the active species, as different species including $\mathrm{Pd}^{0}, \mathrm{Pd}^{+}$and $\mathrm{Pd}^{2+}$ can be present on the surface of the nanoparticles at the same time, and the activity seems to be defined by the balance between $\mathrm{PdO}$ and metallic $\mathrm{Pd}$.49

In case of surface-active ionic liquid $\left[\mathrm{C}_{12} \mathrm{mim}\right] \mathrm{Cl} \mathbf{1}$, the catalytically active species seems to be dependent on the ionic liquid concentration. At high concentrations of $\left[\mathrm{C}_{12} \mathrm{mim}\right] \mathrm{Cl} \mathbf{1}$ no decomposition of the pre-catalyst was observed and poor yields were obtained, indicating that the pre-catalyst was stabilized by the ionic liquid. At lower concentrations, the pre-catalyst decomposes into catalytically active $\mathrm{Pd}$ aggregates. When using $\left[\mathrm{C}_{12} \mathrm{~m}_{2} \mathrm{im}\right] \mathrm{Cl} \mathbf{2}$ the decomposition seems to be independent from concentration of ionic liquid, as constant yields were obtained over the entire concentration range investigated. The different performance of the two ionic liquids at high concentration indicates that the 
co-existence of an homogenous and heterogeneous system, and it seems that the formation of a carbene on the imidazolium group plays a secondary role in the reaction mechanism. Moreover when the reaction mixture was warmed up in absence of the starting material 1-octanol no formation of Palladium aggregates but a light brown solution was obtained, suggesting that to initiate the catalytic cycle the alcohol is initially consumed to reduce Palladium.

\section{Impact of ionic liquid structure}

In order to improve the stabilization of the aggregates forming from the precatalyst decomposition, we expanded the range of surface-active ionic liquids to include dicationic and zwitterionic structures for the oxidation of 1-octanol to octanoic acid (Figure 5 ).

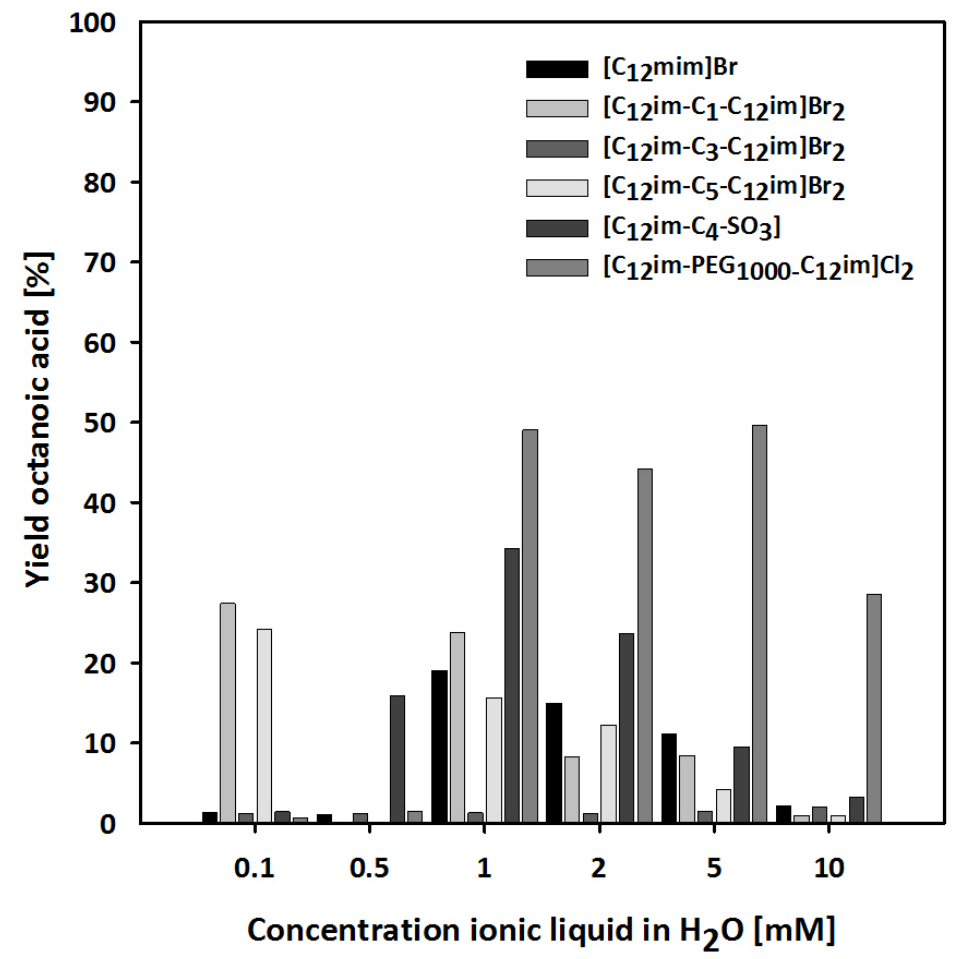

Figure 5: Octainoic acid yield for the oxidation of 1-octanol with the aid of different dicationic and zwitterionic ionic liquids. For reaction conditions see Tab 2.

In order to be able to compare the benefit of dicationic surface-active ionic liquids independently from the anion, $\left[\mathrm{C}_{12} \mathrm{mim}\right] \mathrm{Br} 3$ was tested initially. Only $19 \%$ of octanoic acid were formed at a concentration of $1 \mathrm{mM}$, suggesting that 
$\left[\mathrm{C}_{12} \mathrm{mim}\right] \mathrm{Br}$ is less efficient compared to $\left[\mathrm{C}_{12} \mathrm{mim}\right] \mathrm{Cl}$. Since dicationic surfactants usually present a lower $\mathrm{CMC}$ than the monocationic analogous 35, the dicationic structures $\left[\mathrm{C}_{12} \mathrm{im}-\mathrm{C}_{1}-\mathrm{C}_{12} \mathrm{im}\right] \mathrm{Br}_{2} 4$ and $\left[\mathrm{C}_{12} \mathrm{im}-\mathrm{C}_{5}-\mathrm{C}_{12} \mathrm{im}\right] \mathrm{Br}_{2} 6$ could improve the yield of octanoic acid to $27 \%$ and $24 \%$ respectively using a lower concentration of only $0.1 \mathrm{mM}$. The length of the spacer between the two imidazolium groups has however a strong influence: $\left[\mathrm{C}_{12} \mathrm{im}-\mathrm{C}_{3}-\mathrm{C}_{12} \mathrm{im}\right] \mathrm{Br}_{2} \mathbf{5}$ only

425 afforded traces of the product. Dicationic imidazolium based surfactants have already been reported for the stabilization of silver nanoparticles in water, and the length of the spacer between the imidazolium head groups was found to influence the shape and the size of the formed nanoparticles. In particular very short bridges such as an ethylene bridge favoured the formation of elongated ${ }_{430}$ nanoparticles that could have a less advantageous active surface/volume ratio for catalytic applications. [37. Best results were obtained when testing the PEG-modified zwitterionic ionic liquid [ $\mathrm{C}_{12}$ im-PEG1000- $\left.\mathrm{C}_{12} \mathrm{im}\right] \mathrm{Cl}_{2} 8$ with $50 \%$ yield of octanoic acid in a concentration range between 2 and $5 \mathrm{mM}$. Reports of PEG containing surfactants have shown that they are efficient stabilizer for Pd nanoparticles in water. Examples on the application for hydrogenation and even for the aerobic oxidation of alcohols exist; however, their application towards the oxidation of aliphatic primary alcohols in water is still scarce. 50, 45, 32, 51, 52. Eventually, the zwitterionic surface-active ionic liquid $\left[\mathrm{C}_{12} \mathrm{im}-\mathrm{C}_{4}-\mathrm{SO}_{3}\right] \mathbf{7}$ performed better than the dicationic ones reaching a maximum yield of $35 \%$. Sim-

440 ilar surface-active ionic liquids were found to stabilize Palladium nanoparticles in water via the formation of a double layer, and applications in hydrogenations were reported.29] In any case, it is important to realize that the key to efficient catalysis lies in the appropriate stabilization. If stabilization of the catalytically active species is too high, this would inhibit the reaction, making it challenging to identify intermediate reaction conditions.

\section{From oxygen to air as oxidant}

While pure oxygen was used for the initial screening experiments, the use of air is clearly more attractive and adds considerably to the safety of the process. As can be seen in Figure 6 air could be used instead of oxygen, although a ${ }_{450}$ lower yield of $15 \%$ was obtained with 1 bar air. However, when increasing the pressure to 30 bar the yield could reach $40 \%$. At this conditions the partial pressure of dioxygen is increased up to 6.2 bar. Further investigations on the optimization of the reaction conditions at higher pressure were made and confirmed conditions similar to those used at atmospheric pressure (see ESI Table S1). When comparing the influence of surface-active ionic liquid concentration with oxygen at atmospheric pressure and air at 30 bar it can be noticed that yields are shifted to lower concentration at high pressure compared to the ideal concentration range with oxygen at 1 bar (Figure 6). This is advantageous for the oxidation, as the required amount of the surface-active ionic liquid can be significantly reduced while maintaining the good performance

A similar behaviour was found for the best-performing surface-active ionic liquid $\left[\mathrm{C}_{12} \mathrm{im}-\mathrm{PEG} 1000-\mathrm{C}_{12} \mathrm{im}\right] \mathrm{Cl}_{2} \mathbf{8}$ (Table 4). While yields remained low with air under atmospheric pressure, a strong improvement was obtained using 30 bar 


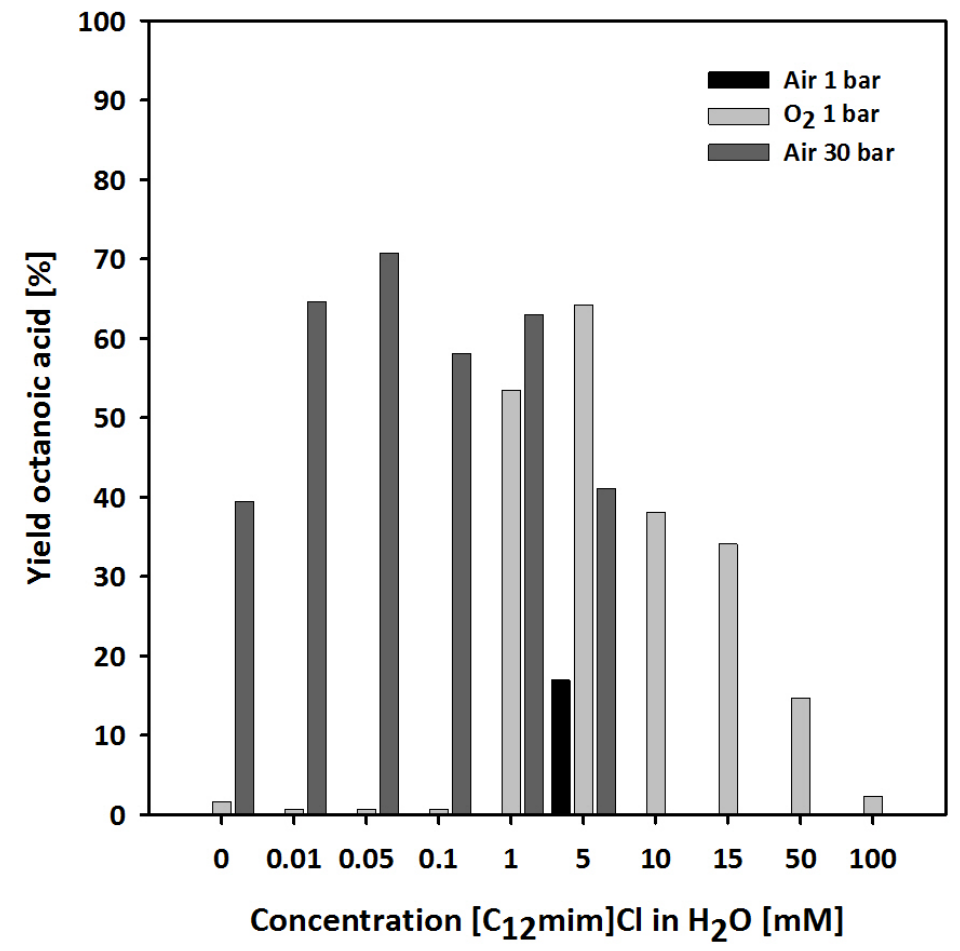

Figure 6: Comparison of the oxidation of 1-octanol to octanoic acid with $\left[\mathrm{C}_{12} \mathrm{mim}\right] \mathrm{Cl}$ at different concentrations with oxygen and air.

of air with $0.05 \mathrm{mM}$ as concentration. Eventually, it was possible to isolate up to $75 \%$ of the product octanoic acid using only small amounts of surface-active ionic liquid in a $0.05 \mathrm{mM}$ solution without further ligands.

\section{Conclusion}

Herein we presented the synthesis and characterization of a series of new and known surface-active 1-dodecyl-3-methylimidazolium-based ionic liquids including dicationic and zwitterionic structures and investigated their aggregation behaviour. [9, 36, 35, 37 These surface-active ionic liquids were applied as sole additive in the aerobic palladium-catalysed oxidation of 1-octanol to octanoic acid in water. Apart from pure oxygen, the system was also operating with air as a cheap, safe and benign oxidant which added considerable to the safety 475 of the process. Among the tested surface-active ionic liquids the best results were obtained with the polyethylenglycol-based ionic liquid $\left[\mathrm{C}_{12}\right.$ im-PEG1000$\left.\mathrm{C}_{12} \mathrm{im}\right] \mathrm{Cl}_{2}$ in a $0.05 \mathrm{mM}$ solution with a pressure of 30 bar air, and up to $75 \%$ yield of pure octanoic acid could be isolated. A strong influence on ionic liquid 
Table 3: Comparison of the oxidation of 1-octanol to octanoic acid with oxygen and air.

\begin{tabular}{lllll}
\hline Ionic liquid $^{\mathrm{a}}$ & $\begin{array}{l}\text { Concentration } \\
{[\mathrm{mM}]}\end{array}$ & Atmosphere & $\begin{array}{l}\text { Pressure } \\
{[\mathrm{bar}]}\end{array}$ & $\begin{array}{l}\text { Yield }^{\mathrm{b}} \\
{[\%]}\end{array}$ \\
\hline$\left[\mathrm{C}_{12} \mathrm{mim}\right] \mathrm{Cl}$ & 5 & oxygen & 1 & 64 \\
{$\left[\mathrm{C}_{12} \mathrm{mim}\right] \mathrm{Cl}$} & 5 & air & 1 & 17 \\
{$\left[\mathrm{C}_{12} \mathrm{mim}\right] \mathrm{Cl}$} & 5 & air & 30 & 40 \\
{$\left[\mathrm{C}_{12} \mathrm{mim}\right] \mathrm{Cl}$} & 0.05 & air & 30 & $71(63)^{\mathrm{c}}$ \\
{$\left[\mathrm{C}_{12} \mathrm{im}-\mathrm{PEG} 1000-\mathrm{C}_{12} \mathrm{im}\right] \mathrm{Cl}_{2}$} & 5 & oxygen & 1 & 50 \\
{$\left[\mathrm{C}_{12} \mathrm{im}-\mathrm{PEG} 1000-\mathrm{C}_{12} \mathrm{im}\right] \mathrm{Cl}_{2}$} & 5 & air & 1 & 14 \\
{$\left[\mathrm{C}_{12} \mathrm{im}-\mathrm{PEG} 1000-\mathrm{C}_{12} \mathrm{im}\right] \mathrm{Cl}_{2}$} & 0.05 & air & 30 & $75(75)^{\mathrm{c}}$ \\
\hline
\end{tabular}

a Reactions performed using $2 \mathrm{mmol}$ of 1-octanol in $10 \mathrm{ml}$ of ionic liquid solution.

b Yield determined via GC analysis.

c Isolated yield reported in brackets.

structure and concentration was found, suggesting that the surface-active ionic species as it has been also observed for Palldium-catalysed cross-coupling in water.29 Optimization of reaction parameters allowed to obtain octanoic acid in good yields, and a number of critical aspects offer advantages to currently available processes for the oxidation of non-activated alcohols in micellar media.

According to previously reported protocols and methods, the oxidation of alcohols in micellar catalysis still relies on the use of stoichiometric organic oxidants [46, 53] or metal oxides as oxidant [54, 55, 56]. Moreover literature deals mainly with activated or short alkyl chain alcohols, which have a considerably higher solubility in water [1, 57, 58. In our system even a small amount of 490 imidazolium based surface-active ionic liquids was very effective in comparison to an ammonium-based surfactant, both in terms of surface activity and for the application in the oxidation of the scarcely reactive primary aliphatic alcohol 1-octanol to octanoic acid. Surface-active ionic liquids significantly improved the yield obtained with pure water, as they could not only overcome the limited solubility of octanol in water but were also able to stabilize the Pd-catalyst in such an extent that no additional ligands or support were required. [48, 24.

Our current research aims to elucidate the interplay between imidazoliumbased surface-active ionic liquid and catalytically active species in this reaction. More studies concerning the concentration-dependent formation and stabiliza-

500 tion of nanoparticles in surface-active ionic liquids for aqueous oxidations and cross coupling reaction are currently under way.

\section{Acknowledgement}

Financial support by the Austrian Science Fund (FWF project P25504-N28) is gratefully acknowledged. 


\section{References}

[1] B. H. Lipshutz, S. Ghorai, Transitioning organic synthesis from organic solvents to water. What's your E factor?, Green Chem. 16 (2014) 36603679. doi:10.1002/adsc.200390057.

[2] T. Dwars, E. Paetzold, G. Oehme, Reactions in micellar systems, Angew. Chem. Int. Ed. 44 (44) (2005) 7174-7199. doi:10.1002/anie.200501365.

[3] G. La Sorella, G. Strukul, A. Scarso, Recent advances in catalysis in micellar media, Green Chem. 17 (2) (2015) 644-683. doi:10.1039/C4GC01368A.

[4] J. Łuczak, J. Hupka, J. Thöming, C. Jungnickel, Self-organization of imidazolium ionic liquids in aqueous solution, Colloids Surf., A 329 (3) (2008) 125-133. doi:10.1016/j.colsurfa.2008.07.012

[5] C. Janiak, Ionic liquids for the synthesis and stabilization of metal nanoparticles, Z. Naturforsch. B Chem. Sci. 68 (10). doi:10.5560/znb.2013-3140

[6] J. Łuczak, C. Jungnickel, M. Markiewicz, J. Hupka, Solubilization of benzene, toluene, and xylene (BTX) in aqueous micellar solutions of am-

$520 \quad$ phiphilic imidazolium ionic liquids, J. Phys. Chem. B 117 (18) (2013) 56535658. doi:10.1021/jp3112205.

[7] A. K. Ressmann, R. Zirbs, M. Pressler, P. Gaertner, K. Bica, Surfaceactive ionic liquids for micellar extraction of piperine from black pepper, Z. Naturforsch. B Chem. Sci. 68b (2013) 1129-1137. doi:10.5560/ZNB. 2013-3196.

[8] K. Bica, P. Gärtner, P. J. Gritsch, A. K. Ressmann, C. Schröder, R. Zirbs, Micellar catalysis in aqueous-ionic liquid systems, Chem. Commun. 48 (41) (2012) 5013-5015. doi:10.1039/c2cc31503c.

[9] A. Cognigni, P. Gaertner, R. Zirbs, H. Peterlik, K. Prochazka, C. Schröder, K. Bica, Surface-active ionic liquids in micellar catalysis: impact of anion selection on reaction rates in nucleophilic substitutions, Phys. Chem. Chem. Phys. 18 (19) (2016) 13375-13384. doi:10.1039/C6CP00493H.

[10] J. Nowicki, J. Łuczak, D. Stańczyk, Dual functionality of amphiphilic 1alkyl-3-methylimidazolium hydrogen sulfate ionic liquids: surfactants with

535 a catalytic function, RSC Adv. 6 (14) (2016) 11591-11601. doi:10.1039/ C5RA23415H.

[11] M. Cokoja, R. M. Reich, M. E. Wilhelm, M. Kaposi, J. Schäffer, D. S. Morris, C. J. Münchmeyer, M. H. Anthofer, I. I. E. Markovits, F. E. Kühn, W. A. Herrmann, A. Jess, J. B. Love, Olefin epoxidation in aqueous phase

540 using ionic-liquid catalysts, ChemSusChem 9 (14) (2016) 1773-1776. doi: $10.1002 /$ cssc. 201600373 . 
[12] M. Hejazifar, M. Earle, K. R. Seddon, S. Weber, R. Zirbs, K. Bica, Ionic liquid-based microemulsions in catalysis, J. Org. Chem. 81 (24) (2016) 12332-12339. doi:10.1021/acs.joc.6b02165.

[13] K. Alfonsi, J. Colberg, P. J. Dunn, T. Fevig, S. Jennings, T. A. Johnson, H. P. Kleine, C. Knight, M. A. Nagy, D. A. Perry, M. Stefaniak, Green chemistry tools to influence a medicinal chemistry and research chemistry based organisation, Green Chem. 10 (1) (2008) 31-36. doi:10.1039/B711717E

[14] C. Parmeggiani, F. Cardona, Transition metal based catalysts in the aerobic oxidation of alcohols, Green Chem. 14 (3) (2012) 547. doi: $10.1039 / \mathrm{c} 2 \mathrm{gc} 16344 \mathrm{f}$

[15] F. Cardona, C. Parmeggiani, Transition metal catalysis in aerobic alcohol oxidation, in: RSC Green Chemistry, Royal Society of Chemistry, 2014, pp. P001-P006.

[16] D. S. Bailie, G. M. A. Clendenning, L. McNamee, M. J. Muldoon, Anionic N,O-ligated $\mathrm{Pd}(\mathrm{II})$ complexes: highly active catalysts for alcohol oxidation, Chem. Commun. 46 (38) (2010) 7238. doi:10.1039/c0cc01138j.

[17] L. M. Dornan, G. M. A. Clendenning, M. B. Pitak, S. J. Coles, M. J. Muldoon, N,O-ligated $\mathrm{Pd}(\mathrm{II})$ complexes for catalytic alcohol oxidation, Catal. Sci. Tech. 4 (8) (2014) 2526. doi:10.1039/c4cy00296b.

[18] C. Melero, O. N. Shishilov, E. Álvarez, P. Palma, J. Cámpora, Well-defined alkylpalladium complexes with pyridine-carboxylate ligands as catalysts for the aerobic oxidation of alcohols, Dalton Trans. 41 (46) (2012) 14087. doi:10.1039/c2dt31728a.

[19] G.-J. ten Brink, I. W. C. E. Arends, R. A. Sheldon, Green, catalytic oxidation of alcohols in water, Science 287 (5458) (2000) 1636-1639. doi: $10.1126 /$ science. 287.5458 .1636 .

[20] G.-J. ten Brink, I. W. C. E. Arends, M. Hoogenraad, G. Verspui, R. A. Sheldon, Catalytic conversions in water. part 22: Electronic effects in the (diimine)palladium(II)-catalysed aerobic oxidation of alcohols, Adv. Synth. Catal. 345 (2003) 497-505. doi:10.1002/adsc. 200390057

[21] R. A. Sheldon, Recent advances in green catalytic oxidations of alcohols in aqueous media, Catal. Today 247 (2015) 4-13. doi:10.1016/j.cattod. 575 2014.08.024

[22] E. Levin, E. Ivry, C. E. Diesendruck, N. G. Lemcoff, Water in Nheterocyclic carbene-assisted catalysis, Chem. Rev. 115 (11) (2015) 46074692. doi:10.1021/cr400640e 
[23] B. S. Cho, I. G. Jung, Y. K. Chung, J. W. Han, Palladium-catalyzed aerobic oxidation reaction of 1-heptanol in water using water-soluble N-heterocyclic carbene ligands, Bull. Korean Chem. Soc. 36 (2015) 451-452. doi:10. 1002/bkcs.10105.

[24] M. Mifsud, K. V. Parkhomenko, I. W. Arends, R. A. Sheldon, Pd nanoparticles as catalysts for green and sustainable oxidation of functionalized alcohols in aqueous media, Tetrahedron 66 (5) (2010) 1040-1044. doi: $10.1016 / j$.tet.2009.11.007.

[25] M. Vasiloiu, P. Gaertner, R. Zirbs, K. Bica, Coordinating chiral ionic liquids: Design, synthesis, and application in asymmetric transfer hydrogenation under aqueous conditions, Eur. J. Org. Chem. 2015 (11) (2015) 23742381. doi:10.1002/ejoc.201403555

[26] M. Vasiloiu, D. Rainer, P. Gaertner, C. Reichel, C. Schröder, K. Bica, Basic chiral ionic liquids: A novel strategy for acid-free organocatalysis, Catal.

11 Today 200 (2013) 80 - 86. doi:http://dx.doi.org/10.1016/j.cattod. 2012.07.002.

[27] R. Nissim, C. Batchelor-McAuley, R. G. Compton, Measuring oxygen

口 solubility in micelles, ChemElectroChem 3 (1) (2016) 105-109. doi: 10.1002/celc. 201500380 .

[28] W. Zhu, Y. Yu, H. Yang, L. Hua, Y. Qiao, X. Zhao, Z. Hou, Cooperative effects in catalytic hydrogenation regulated by both the cation and anion of an ionic liquid, Chem. Eur. J. 19 (6) (2013) 2059-2066. doi:10.1002/ chem.201202707.

[29] B. S. Souza, E. C. Leopoldino, D. W. Tondo, J. Dupont, F. Nome, Imidazolium-based zwitterionic surfactant: a new amphiphilic Pd nanoparticle stabilizing agent, Langmuir 28 (1) (2012) 833-840. doi:10.1021/

[30] C. Pardin, L. Leclercq, A. Schmitzer, $N, N^{\prime}$-methylenediimidazolium salts: From self-assembly to an efficient DNAse protection system, Chem. Eur. J. 16 (15) (2010) 4686-4692. doi:10.1002/chem.200902794.

[31] H. Li, Y. Qiao, L. Hua, Z. Hou, B. Feng, Z. Pan, Y. Hu, X. Wang, X. Zhao, Y. Yu, Imidazolium polyoxometalate: An ionic liquid catalyst for esterification and oxidative esterification, ChemCatChem 2 (9) (2010) 1165-1170. doi:10.1002/cctc. 201000021 .

[32] W. Zhu, H. Yang, Y. Yu, L. Hua, H. Li, B. Feng, Z. Hou, Amphiphilic ionic liquid stabilizing palladium nanoparticles for highly efficient catalytic 615 hydrogenation, Phys. Chem. Chem. Phys. 13 (30) (2011) 13492-13500. doi:10.1039/c1cp20255c. 
[33] J. M. Grill, J. W. Ogle, S. A. Miller, An efficient and practical system for the catalytic oxidation of alcohols, aldehydes, and $\alpha, \beta$-unsaturated carboxylic acids, J. Org. Chem. 71 (25) (2006) 9291-9296. doi:10.1021/jo0612574.

[34] A. E. Bradley, C. Hardacre, J. D. Holbrey, S. Johnston, S. E. J. McMath, M. Nieuwenhuyzen, Small-angle X-ray scattering studies of liquid crystalline 1-alkyl-3-methylimidazolium salts, Chem. Mat. 14 (2) (2002) 629635. doi:10.1021/cm010542v.

[35] Q. Q. Baltazar, J. Chandawalla, K. Sawyer, J. L. Anderson, Interfacial and micellar properties of imidazolium-based monocationic and dicationic ionic liquids, Colloids Surf., A 302 (1) (2007) 150-156. doi:10.1016/j. colsurfa.2007.02.012

[36] M. Blesic, M. H. Marques, N. V. Plechkova, K. R. Seddon, L. P. N. Rebelo, A. Lopes, Self-aggregation of ionic liquids: micelle formation in aqueous solution, Green Chem. 9 (2007) 481-490. doi:10.1039/B615406A

[37] S. Datta, J. Biswas, S. Bhattacharya, How does spacer length of imidazolium gemini surfactants control the fabrication of 2D-langmuir films of silver-nanoparticles at the airwater interface?, J. Colloid Interface Sci. 430 (2014) 85-92. doi:10.1016/j.jcis.2014.05.018

[38] C.-J. Cheng, G.-M. Qu, J.-J. Wei, T. Yu, W. Ding, Thermodynamics of micellization of sulfobetaine surfactants in aqueous solution, J. Surfactants Deterg. 15 (6) (2012) 757-763. doi:10.1007/s11743-012-1374-8.

[39] C. Ren, F. Wang, Z. Zhang, H. Nie, N. Li, M. Cui, Synthesis, surface activity and aggregation behavior of gemini imidazolium surfactants 1,3bis(3-alkylimidazolium-1-yl) propane bromide, Colloids Surf., A 467 (2015) 1-8. doi:10.1016/j.colsurfa.2014.11.031

[40] S. L. Desset, S. W. Reader, D. J. Cole-Hamilton, Aqueous-biphasic hydroformylation of alkenes promoted by weak surfactants, Green Chem. 11 (5) (2009) 630. doi:10.1039/b822139a.

[41] J. Łuczak, M. Markiewicz, J. Thöming, J. Hupka, C. Jungnickel, Influence of the hofmeister anions on self-organization of 1-decyl-3methylimidazolium chloride in aqueous solutions, J. Colloid Interface Sci. 362 (2) (2011) 415-422. doi:10.1016/j.jcis.2011.06.058.

[42] M. K. Starchevsky, S. L. Hladiy, Y. A. Pazdersky, M. N. Vargaftik, I. I. Moiseev, Giant Pd-561 clusters: onset to new catalytic properties, J. Mol. Catal. A: Chem. 146 (1) (1999) 229-236. doi:10.1016/S1381-1169(99) 00086-2

[43] G. Kovtun, T. Kameneva, S. Hladyi, M. Starchevsky, Y. Pazdersky, I. Stolarov, M. Vargaftik, I. Moiseev, Oxidation, redox disproportionation and chain termination reactions catalysed by the Pd-561 giant cluster, Adv. 
Synth. Catal 344 (2002) 957 - 964. doi:10.1002/1615-4169(200210) 344: 9<957::AID-ADSC957>3.0.CO;2-V.

[44] A. Ohtaka, R. Kuroki, T. Teratani, T. Shinagawa, G. Hamasaka, Y. Uozumi, O. Shimomura, R. Nomura, Recovery of in situ-generated Pd nanoparticles with linear polystyrene, Green Sustainable Chem. 01 (2) (2011) 19-25. doi:10.4236/gsc.2011.12004.

[45] G. Giachi, W. Oberhauser, M. Frediani, E. Passaglia, L. Capozzoli, L. Rosi, Pd-nanoparticles stabilized by pyridine-functionalized poly(ethylene glycol) as catalyst for the aerobic oxidation of $\alpha, \beta$-unsaturated alcohols in water,

665 J. Polym. Sci., Part A: Polym. Chem. 51 (11) (2013) 2518-2526. doi: $10.1002 /$ pola.26645

[46] C. Zhu, Y. Wei, L. Ji, Catalytic oxidation of alcohols to corresponding aldehydes or ketones with TEMPO-mediated iodosobenzene in water in the presence of a surfactant, Synth. Commun. 40 (14) (2010) 2057-2066. doi:10.1080/00397910903219427.

[47] S. E. Davis, M. S. Ide, R. J. Davis, Selective oxidation of alcohols and aldehydes over supported metal nanoparticles, Green Chem. 15 (1) (2013) 17-45. doi:10.1039/C2GC36441G.

[48] S. Rostamnia, E. Doustkhah, Z. Karimi, S. Amini, R. Luque, Surfactantexfoliated highly dispersive pd-supported graphene oxide nanocomposite as a catalyst for aerobic aqueous oxidations of alcohols, ChemCatChem 7 (11) (2015-06-01) 1678-1683. doi:10.1002/cctc.201500126.

[49] C. V. Gaskell, C. M. A. Parlett, M. A. Newton, K. Wilson, A. F. Lee, Redox-controlled crotyl alcohol selective oxidation: In situ oxidation and reduction dynamics of catalytic Pd nanoparticles via syn-

प chronous XANES/MS, ACS Catal. 2 (11) (2012) 2242-2246. doi:10.1021/ cs300445y.

[50] B. Feng, Z. Hou, H. Yang, X. Wang, Y. Hu, H. Li, Y. Qiao, X. Zhao, Q. Huang, Functionalized poly(ethylene glycol)-stabilized water-soluble palladium nanoparticles: property/activity relationship for the aerobic

1. alcohol oxidation in water, Langmuir 26 (4) (2010) 2505-2513. doi: 10.1021/la9027755.

[51] E. Drinkel, F. D. Souza, H. D. Fiedler, F. Nome, The chameleon effect in zwitterionic micelles: Binding of anions and cations and use as nanoparticle stabilizing agents, Curr. Opin. Colloid Interface Sci. 18 (1) (2013) 26-34. doi:10.1016/j.cocis.2013.01.001

[52] D. W. Tondo, E. C. Leopoldino, B. S. Souza, G. A. Micke, A. C. O. Costa, H. D. Fiedler, C. A. Bunton, F. Nome, Synthesis of a new zwitterionic surfactant containing an imidazolium ring. Evaluating the chameleon-like behavior of zwitterionic micelles, Langmuir 26 (20) (2010) 15754-15760. doi:10.1021/la102391e. 
[53] S. Pandey, S. K. Upadhyay, Effect of cationic micellar aggregates on the kinetics of oxidation of aminoalcohols by n-bromosuccinimide in alkaline medium, J. Colloid Interf. Sc. 285 (2) (2005) 789-794. doi:10.1016/j. jcis.2004.01.085.

[54] P. Sar, A. Ghosh, S. Malik, D. Ray, B. Das, B. Saha, Selective heteroaromatic nitrogen base promoted chromium(VI) oxidation of isomeric pentanols in aqueous micellar media at room temperature, J. Ind. Eng. Chem. 42 (2016) 53-62. doi:10.1016/j.jiec.2016.07.028.

[55] P. Bhattacharyya, A. Ghosh, B. Saha, Room temperature micellar catalysis on permanganate oxidation of butanol to butanal in aqueous medium at

n atmospheric pressure, Tenside Surfact. Det. 52 (1) (2015) 36-40. doi: $10.3139 / 113.110346$

[56] A. Ghosh, R. Saha, B. Saha, Effect of CHAPS and CPC micelles on ir(III) catalyzed ce(IV) oxidation of aliphatic alcohols at room temperature and pressure, J. Mol. Liq. 196 (2014) 223-237. doi:10.1016/j.molliq. 2014. 03.037

[57] B.-T. Chen, K. V. Bukhryakov, R. Sougrat, V. O. Rodionov, Enzymeinspired functional surfactant for aerobic oxidation of activated alcohols to

715 aldehydes in water, ACS Catalysis 5 (2) (2015) 1313-1317. doi:10.1021/ Cs5020018.

[58] M. Bettoni, L. Brinchi, T. Del Giacco, R. Germani, S. Meniconi, C. Rol, G. V. Sebastiani, Surfactant effect on titanium dioxide photosensitized oxidation of 4-dodecyloxybenzyl alcohol, J. Photochem. Photobiol. A Chem. 229 (1) (2012) 53-59. doi:10.1016/j.jphotochem.2011.12.003. 


\section{Figure Captions}

Figure 1: Synthesis of surface-active ionic liquids.

Figure 21: Surface tension of the investigated ionic liquids at $25^{\circ} \mathrm{C}$.

725

Figure 3 :Conductivity of the investigated ionic liquids at $25{ }^{\circ} \mathrm{C}$.

Figure 4:Results for the oxidation of 1-octanol performed with $\left[\mathrm{C}_{12} \mathrm{mim}\right] \mathrm{Cl}$ (dark grey) and $\left[\mathrm{C}_{12} \mathrm{~m}_{2} \mathrm{im}\right] \mathrm{Cl}$ (light gray) at different concentrations. For reaction conditions see Tab.2.

Figure 5: Octainoic acid yield for the oxidation of 1-octanol with the aid of different dicationic and zwitterionic ionic liquids. For reaction conditions see Tab 2.

735

Figure 6 :Comparison of the oxidation of 1-octanol to octanoic acid with $\left[\mathrm{C}_{12} \mathrm{mim}\right] \mathrm{Cl}$ at different concentrations with oxygen and air. 
Tables

Table 1: Critical micelle concentration (CMC) obtained by surface tension and conductivity for surface-active ionic liquids 1-8.

\begin{tabular}{lll}
\hline Ionic Liquid & $\begin{array}{l}\text { Surface tension } \\
{[\mathrm{mM}]}\end{array}$ & $\begin{array}{l}\text { Conductivity } \\
{[\mathrm{mM}]}\end{array}$ \\
\hline$\left[\mathrm{C}_{12} \mathrm{mim}\right] \mathrm{Cl} \mathbf{1}$ & $13.25[9]$ & $14.53[9]$ \\
{$\left[\mathrm{C}_{12} \mathrm{~m}_{2} \mathrm{im}\right] \mathrm{Cl} \mathbf{2}$} & 10.33 & 13.75 \\
{$\left[\mathrm{C}_{12} \mathrm{mim}\right] \mathrm{Br} \mathbf{3}$} & $9.29[9]$ & $10.29[9]$ \\
{$\left[\mathrm{C}_{12} \mathrm{im}-\mathrm{C}_{1}-\mathrm{C}_{12} \mathrm{im}\right] \mathrm{Br}_{2} \mathbf{4}$} & 0.70 & 0.74 \\
{$\left[\mathrm{C}_{12} \mathrm{im}-\mathrm{C}_{3}-\mathrm{C}_{12} \mathrm{im}\right] \mathrm{Br}_{2} \mathbf{5}$} & $0.53[39]$ & $0.61[39]$ \\
{$\left[\mathrm{C}_{12} \mathrm{im}-\mathrm{C}_{5}-\mathrm{C}_{12} \mathrm{im}\right] \mathrm{Br}_{2} \mathbf{6}$} & 0.63 & 0.70 \\
{$\left[\mathrm{C}_{12} \mathrm{im}_{-} \mathrm{C}_{4}-\mathrm{SO}_{3}\right] \mathbf{7}$} & 1.67 & - \\
{$\left[\mathrm{C}_{12} \mathrm{im}-\mathrm{PEG} \mathrm{P} 1000-\mathrm{C}_{12} \mathrm{im}\right] \mathrm{Cl}_{2} \mathbf{8}$} & 2.26 & 2.91 \\
\hline
\end{tabular}


Table 2: Optimization of the reaction conditions for the oxidation of 1-octanol using 1 bar of $\mathrm{O}_{2}$ as oxidizing agent.

\begin{tabular}{llllll}
\hline Entry $^{\mathrm{a}}$ & $\begin{array}{l}\text { Temperature } \\
{\left[{ }^{\circ} \mathrm{C}\right]}\end{array}$ & $\begin{array}{l}\text { Time } \\
{[\mathrm{h}]}\end{array}$ & $\begin{array}{l}\mathrm{Pd}(\mathrm{OAc})_{2} \\
{[\mathrm{~mol} . \%]}\end{array}$ & $\begin{array}{l}\mathrm{K}_{2} \mathrm{CO}_{3} \\
{[\mathrm{~mol} . \%]}\end{array}$ & $\begin{array}{l}\mathrm{Yield}^{\mathrm{b}} \\
{[\%]}\end{array}$ \\
\hline 1 & 100 & 18 & 5 & 20 & 10 \\
2 & 100 & 18 & 5 & 50 & 64 \\
3 & 100 & 18 & 5 & 75 & 65 \\
4 & 100 & 18 & 5 & 100 & 48 \\
5 & 100 & 18 & 5 & $50^{\mathrm{c}}$ & $<5$ \\
6 & 100 & 18 & 5 & $50^{\mathrm{d}}$ & $<5$ \\
7 & 100 & 18 & 2 & 50 & $<5$ \\
8 & 100 & 18 & 10 & 50 & 56 \\
9 & 100 & 18 & $2.5^{\mathrm{e}}$ & 50 & 58 \\
10 & 25 & 18 & 5 & 50 & $<5$ \\
11 & 50 & 18 & 5 & 50 & $<5$ \\
12 & 80 & 18 & 5 & 50 & 42 \\
13 & 100 & 6 & 5 & 50 & $<5$ \\
14 & 100 & 12 & 5 & 50 & 48 \\
15 & 100 & 24 & 5 & 50 & 71 \\
16 & 100 & 48 & 5 & 50 & 64 \\
$17^{\mathrm{f}}$ & 100 & 18 & 5 & 50 & 5 \\
\hline
\end{tabular}

${ }^{\text {a }}$ Reactions performed using $0.4 \mathrm{mmol}$ of 1-octanol in $2 \mathrm{ml}$ of a $5 \mathrm{mM}\left[\mathrm{C}_{12} \mathrm{mim}\right] \mathrm{Cl}$ solution.

${ }^{\mathrm{b}}$ Yield determined via GC analysis. Results are reported as average of two independent experiments.

${ }^{c}$ DBU used as base.

d $\mathrm{NaOAc}$ used as base.

e $[\mathrm{Pd}(\text { allyl }) \mathrm{Cl}]_{2}$ used as catalyst.

${ }^{\mathrm{f}}$ Reactions performed with a $5 \mathrm{mM}$ solution of CTAB instead of $\left[\mathrm{C}_{12} \mathrm{mim}\right] \mathrm{Cl}$ solution. 
Table 3: Comparison of the oxidation of 1-octanol to octanoic acid with oxygen and air.

\begin{tabular}{|c|c|c|c|c|}
\hline Ionic liquid ${ }^{\mathrm{a}}$ & $\begin{array}{l}\text { Concentration } \\
{[\mathrm{mM}]}\end{array}$ & Atmosphere & $\begin{array}{l}\text { Pressure } \\
\text { [bar] }\end{array}$ & $\begin{array}{l}\text { Yield }^{\mathrm{b}} \\
{[\%]}\end{array}$ \\
\hline$\left[\mathrm{C}_{12} \mathrm{mim}\right] \mathrm{Cl}$ & 5 & oxygen & 1 & 64 \\
\hline$\left[\mathrm{C}_{12} \mathrm{mim}\right] \mathrm{Cl}$ & 5 & air & 1 & 17 \\
\hline$\left[\mathrm{C}_{12} \mathrm{mim}\right] \mathrm{Cl}$ & 5 & air & 30 & 40 \\
\hline$\left[\mathrm{C}_{12} \mathrm{mim}\right] \mathrm{Cl}$ & 0.05 & air & 30 & $71(63)^{\mathrm{c}}$ \\
\hline$\left[\mathrm{C}_{12} \mathrm{im}-\mathrm{PEG} 1000-\mathrm{C}_{12} \mathrm{im}\right] \mathrm{Cl}_{2}$ & 5 & oxygen & 1 & 50 \\
\hline$\left[\mathrm{C}_{12} \mathrm{im}-\mathrm{PEG} 1000-\mathrm{C}_{12} \mathrm{im}\right] \mathrm{Cl}_{2}$ & 5 & air & 1 & 14 \\
\hline$\left[\mathrm{C}_{12} \mathrm{im}-\mathrm{PEG} 1000-\mathrm{C}_{12} \mathrm{im}\right] \mathrm{Cl}_{2}$ & 0.05 & air & 30 & $75(75)^{\mathrm{c}}$ \\
\hline
\end{tabular}

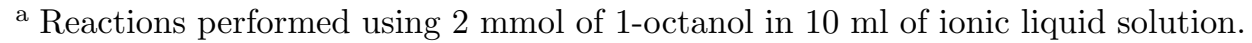

b Yield determined via GC analysis.

${ }^{\text {c }}$ Isolated yield reported in brackets. 